\title{
Alternating offers bargaining with loss aversion
}

Citation for published version (APA):

Driesen, B. W. I., Perea ý Monsuwé, A., \& Peters, H. J. M. (2009). Alternating offers bargaining with loss aversion. METEOR, Maastricht University School of Business and Economics. METEOR Research Memorandum No. 001 https://doi.org/10.26481/umamet.2009001

Document status and date:

Published: 01/01/2009

DOI:

10.26481/umamet.2009001

Document Version:

Publisher's PDF, also known as Version of record

\section{Please check the document version of this publication:}

- A submitted manuscript is the version of the article upon submission and before peer-review. There can be important differences between the submitted version and the official published version of record.

People interested in the research are advised to contact the author for the final version of the publication, or visit the DOI to the publisher's website.

- The final author version and the galley proof are versions of the publication after peer review.

- The final published version features the final layout of the paper including the volume, issue and page numbers.

Link to publication

\footnotetext{
General rights rights.

- You may freely distribute the URL identifying the publication in the public portal. please follow below link for the End User Agreement:

www.umlib.nl/taverne-license

Take down policy

If you believe that this document breaches copyright please contact us at:

repository@maastrichtuniversity.nl

providing details and we will investigate your claim.
}

Copyright and moral rights for the publications made accessible in the public portal are retained by the authors and/or other copyright owners and it is a condition of accessing publications that users recognise and abide by the legal requirements associated with these

- Users may download and print one copy of any publication from the public portal for the purpose of private study or research.

- You may not further distribute the material or use it for any profit-making activity or commercial gain

If the publication is distributed under the terms of Article $25 \mathrm{fa}$ of the Dutch Copyright Act, indicated by the "Taverne" license above, 
Bram Driesen, Andrés Perea, Hans Peters

Alternating offers bargaining with loss aversion

$\mathrm{RM} / 09 / 001$

JEL code: C78

\section{METEबrR}

Maastricht research school of Economics of TEchnology and ORganizations

Universiteit Maastricht

Faculty of Economics and Business Administration

P.O. Box 616

NL - 6200 MD Maastricht

phone : ++31433883830

fax $\quad$ : ++31433884873 


\title{
Alternating offers bargaining with loss aversion
}

\author{
Bram Driesen* $\quad$ Andrés Perea* Hans Peters*
}

This version, January 2009

\begin{abstract}
The Rubinstein alternating offers bargaining game is reconsidered under the assumption that each player is loss averse and the associated reference point is equal to the highest turned down offer of the opponent in the past. This makes the payoffs and therefore potential equilibrium strategies dependent on the history of play. A subgame perfect equilibrium is constructed, in which the strategies depend on the history of play through the current reference points. It is shown that this equilibrium is unique under some assumptions that it shares with the equilibrium in the classical model: immediate acceptance of equilibrium offers, indifference between acceptance and rejection of such offers, and strategies depending only on the current reference points. It is also shown that in this equilibrium loss aversion is a disadvantage. Moreover, a relation with asymmetric Nash bargaining is established, where a player's bargaining power is negatively related to own loss aversion and positively to the opponent's loss aversion.
\end{abstract}

JEL-Classification: C78

Keywords: Bargaining, Alternating offers, Loss aversion, Reference-dependence.

\section{Introduction}

One of the characteristics of the Ståhl (1972) and Rubinstein (1982) non-cooperative approach to the classical problem of dividing a pie between two players is that preferences are time dependent but do not otherwise depend on the history of play of the game. In real life bargaining situations it is very likely that this assumption is violated and that the share of the pie that an agent finally obtains is evaluated in terms of the history of offers and counter-offers made so far. In particular, it is likely that a share of $x \%$ is evaluated less if a share of $y \%$ with $y>x$ has been within reach at an earlier stage of the game.

* Department of Quantitative Economics, University of Maastricht, P.O. Box 616, 6200 MD Maastricht, The Netherlands. Telephone: +31-43-3883835. Telefax: +31-43-3884874. Email adresses: B.Driesen@ke.unimaas.nl, A.Perea@ke.unimaas.nl, H.Peters@ke.unimaas.nl. 
This is the phenomenon of loss aversion, and the objective of this paper is to study the effect of loss aversion in the Rubinstein alternating offers bargaining game.

Loss aversion was introduced by Kahneman and Tversky (1979). We adopt the simple and elegant version of Shalev (2002). In this version, an agent's preference is characterized by a basic utility function, a reference point, and a loss aversion coefficient: outcomes below the reference point are regarded as losses and their basic utility values are scaled down by the loss aversion factor. It is essential that this reference point be endogenous (see Kahneman and Tversky, 1984). In particular, in a game-theoretic context, what is regarded as a loss is likely to depend on the (history of play of the) game.

In the present paper we make the natural assumption that the reference point of a player is equal to the highest turned down offer of the opponent, since that represents the share of the pie that could have been obtained with certainty so far. It turns out that this results in a non-trivial modification of the Rubinstein alternating offers bargaining game: through changed reference points the game with loss aversion depends on the history of play. Indeed, while all subgames in the classical Rubinstein model starting with either a proposal by a player or an acceptance/rejection decision are essentially identical, in our case these subgames depend on the effect the history of play has on preferences. This makes the analysis of the game and, in particular, the characterization of subgame perfect equilibria, much more complicated.

Thus, we consider the Rubinstein alternating offers bargaining game with loss averse players, where the discount factor is interpreted as the probability of continuation of the game after rejection of a proposal. For this game, we construct a subgame perfect equilibrium that shares some features with the subgame perfect equilibrium of the classical game without loss aversion: immediate acceptance of equilibrium offers - implying that agreement is reached immediately as well; indifference between acceptance and rejection of such offers; and strategies depending only on the current reference points. It turns out that the equilibrium strategies depend on nine different regions describing the location of the players' reference points. For instance, if the reference points are high then we are essentially back in the classical case since higher offers are not going to be made in equilibrium and, thus, the reference points will no longer change. But if reference points are low - we assume them to be zero initially - then the equilibrium proposals are influenced by the possibility of future higher reference points. We also show that the constructed equilibrium is the unique subgame perfect equilibrium with the three mentioned properties, but have to leave it as an open problem whether these properties are necessary for uniqueness.

We include an extensive comparative statics analysis of the constructed subgame perfect equilibrium. We establish the intuitive result that higher loss aversion leads to a lower equilibrium share of the pie. We also extend our results to the case of different discount factors (probabilities of continuation of the game), and to more general (increasing and concave) basic utility functions. Finally, we establish an asymptotic relation with non-symmetric Nash bargaining solutions, in the spirit of Binmore et al. (1986). In particular, we show 
that a player's bargaining power is negatively related to own loss aversion and positively to the opponent's loss aversion.

\section{Further related literature}

Loss aversion with a fixed reference point can be regarded as a special case of risk aversion. The effect of risk aversion in the Nash (1950) and Rubinstein (1982) bargaining models has been studied before, initially in Kihlstrom et al. (1981) and Roth (1985) in the context of expected utility. For the more general context of rank dependent utility, see Safra and Zilcha (1993) and Köbberling and Peters (2003). In all this work the utility functions are fixed and do not change as a result of (play of) the game.

Closer to the present context is Shalev (2002), who applies a loss aversion transformation to the discount factor, and obtains the unique subgame perfect equilibrium of Rubinstein with the transformed discount factors. Li (2007) assumes that bargainers prefer disagreement over any share that is below the highest they have been offered in the past, and finds a unique subgame perfect equilibrium in this setting. Thus, Li's way of updating reference points during play of the game bears some resemblance with our approach. However, Li assumes that reference points grow over time. Moreover, the utility functions in Li's model have a discontinuous jump that explicitly ensures that, in equilibrium, each offer made to a player exceeds the previous offer made to that player.

Compte and Jehiel (2003) assume that after breakdown of the negotiations, the game starts anew at a fixed cost. The first mover is randomly chosen from the two bargainers, and in each such new bargaining phase, they have a constant reference point which is based on the proposals made in the previous phases. The subgame perfect equilibrium they find in this setting has in common with Li's that bargainers do not achieve agreement instantaneously.

\section{Organization of the paper}

Section 2 describes the model and in Section 3 we construct a subgame perfect equilibrium. Section 4 concerns uniqueness of this equilibrium, and Section 5 collects our comparative statics results. Section 6 concludes. Because of their length, all proofs are collected in three Appendices A, B, and C.

\section{The alternating offers bargaining model with loss aversion}

In this section we describe the alternating offers bargaining model of Rubinstein (1982) and introduce the concept of loss aversion in this model. We will try to be as nontechnical as is possible without becoming imprecise. A completely formal treatment is presented in Appendix A. 
One unit of a perfectly divisible good, the pie, has to be divided among two bargainers, 1 and 2. The set of all possible partitions of the pie is denoted as

$$
Z:=\left\{\left(z_{1}, z_{2}\right) \in \mathbb{R}^{2} \mid z_{1}+z_{2}=1, z_{1}, z_{2} \geq 0\right\} .
$$

Bargaining takes place at time $t=1,2, \ldots$ At odd moments, player 1 makes a proposal $z=\left(z_{1}, z_{2}\right) \in Z$ and player 2 decides to accept $(Y)$ or to reject $(N)$ this proposal. At even moments, the roles of the players are reversed. If a proposal $\left(z_{1}, z_{2}\right) \in Z$ is accepted, then the game ends and each player $i$ obtains $z_{i}$. If a proposal is rejected then the game continues to the next moment with probability $0<\delta<1$, and stops with probability $1-\delta$. In the latter case, the game ends in disagreement and no player receives anything, i.e., the shares $(0,0)$ result. If the game continues forever - which happens with probability 0 - then again the shares $(0,0)$ result.

A strategy $f$ for player 1 in this game specifies for each odd moment a proposal in $Z$, where this proposal may depend on the complete history of play of the game so far; and for each even moment an answer $Y$ or $N$, where this answer may depend on the current proposal and on the rest of the history of play of the game. A strategy $g$ of player 2 is defined similarly, with the roles of odd and even moments reversed.

So far, this is the Rubinstein alternating offers mechanism. From here, however, we deviate by assuming that the players are loss averse. We assume that the basic utility for a player $i$ of obtaining a share $z_{i}$ of the pie is just equal to $z_{i}{ }^{1}{ }^{1}$ but that shares $z_{i}$ below some reference point $r_{i} \in[0,1]$ are regarded as losses and scaled down by a loss aversion coefficient $\lambda_{i} \geq 0$. More precisely, player $i$ evaluates $z_{i}$ by the function

$$
w\left(z_{i}, r_{i}, \lambda_{i}\right):= \begin{cases}z_{i} & \text { if } z_{i} \geq r_{i} \\ z_{i}-\lambda_{i}\left(r_{i}-z_{i}\right) & \text { if } z_{i}<r_{i}\end{cases}
$$

or, equivalently, by

$$
w\left(z_{i}, r_{i}, \lambda_{i}\right)=\left(1+\lambda_{i}\right) z_{i}-\lambda_{i} \max \left\{r_{i}, z_{i}\right\} .
$$

Loss aversion was first introduced by Kahneman and Tversky (1979). We use the simplified version of Shalev (2002). We assume that the loss aversion coefficients of the bargainers are given and fixed. The reference points of the players, however, are determined endogenously, in the following way. ${ }^{2}$ At some moment $t$, consider all the offers made to player $i$ by the other player $j$ so far, possibly including the offer that is on the table at moment $t$. These represent all the shares of the pie that player $i$ could have obtained up to this moment with certainty. Then, it is natural to assume that the maximum of those shares is player $i$ 's reference point, since this is what he could have obtained: lower shares

\footnotetext{
${ }^{1}$ This assumption will be relaxed in Section 5 .

${ }^{2}$ Endogeneity of the reference point is an essential assumption in prospect theory, see Kahneman and Tversky (1984). If we would assume exogenous, fixed reference points then our model would reduce to a special case of the standard Rubinstein bargaining model.
} 
represent losses with respect to this reference point, and are evaluated according to $(1)$.

Thus, we assume that the initial reference points are 0 and write $r_{1}^{0}=r_{2}^{0}=0$; and that at any moment $t \geq 1$, player 1 's and 2 's reference points are equal to

$$
r_{1}^{t}=\max \left\{0, z_{1}^{s} \mid s=2,4, \ldots \leq t\right\}, r_{2}^{t}=\max \left\{z_{2}^{s} \mid s=1,3, \ldots \leq t\right\}
$$

if $z^{1}, z^{2}, \ldots, z^{t} \in Z$ are the proposals made up to time $t$. Observe that incorporating loss aversion in this natural way causes a crucial difference with the classical Rubinstein bargaining game: the game is no longer history independent. For instance, subgames starting at odd moments are no longer identical copies of the whole game, since reference points and therefore payoff functions may have changed during the play of the game.

Recall that the unique subgame perfect equilibrium (SPE) in the classical Rubinstein bargaining game (without loss aversion) has the following characteristics: (i) it is time and history independent, that is, players always make and accept the same proposals; (ii) in equilibrium every proposal is immediately accepted; and (iii) in equilibrium a player is always indifferent between acceptance and rejection. Also in our model with loss aversion we look for an SPE but, clearly, we cannot expect to find a history independent equilibrium. In the next section, we will construct an SPE in which, instead, the strategies of the players are stationary Markov strategies: proposals and acceptance/rejection decisions depend only on the current reference points, and not on time or on the history of play of the game otherwise than through the effect on reference points. This equilibrium will still satisfy (ii) and (iii) and, in fact, we will show that it is the unique SPE with stationary Markov strategies and satisfying (ii) and (iii). Whether dropping one or more of these three conditions allows for different SPE is an open question.

\section{A subgame perfect equilibrium}

Heuristically, the SPE in the Rubinstein model is based on the idea that the proposal of a player $i$ should make his opponent $j$ indifferent between that proposal and the proposal of $j$ himself in the next round. We will employ the same idea to construct an SPE in our model with loss averse players.

Consider an odd time moment $t$, where player 1 makes a proposal $x \in Z$. Suppose that after rejection player 2 makes the proposal $y \in Z$ at time $t+1$. Let $r_{2}$ be player 2's reference point at time $t-1$ (so $r_{2}=x_{2}$ at $t=1$ ). To make player 2 accept the proposal $x$ we would need

$$
\begin{aligned}
& \left(1+\lambda_{2}\right) x_{2}-\lambda_{2} \max \left\{r_{2}, x_{2}\right\} \geq \\
& \delta\left[\left(1+\lambda_{2}\right) y_{2}-\lambda_{2} \max \left\{y_{2}, \max \left\{r_{2}, x_{2}\right\}\right\}\right]-(1-\delta) \lambda_{2} \max \left\{r_{2}, x_{2}\right\} .
\end{aligned}
$$

That is, player 2 should value the offer $x$ at time $t$ at least as highly as his own offer $y$ in the next period after having rejected $x$. The analogous inequality at 
even moments is

$$
\begin{aligned}
&\left(1+\lambda_{1}\right) y_{1}-\lambda_{1} \max \left\{r_{1}, y_{1}\right\} \geq \\
& \delta\left[\left(1+\lambda_{1}\right) x_{1}-\lambda_{1} \max \left\{x_{1}, \max \left\{r_{1}, y_{1}\right\}\right\}\right]-(1-\delta) \lambda_{1} \max \left\{r_{1}, y_{1}\right\}
\end{aligned}
$$

To construct the equilibrium, we assume that the inequalities (2) and (3) are equalities. Let $\mu_{i}:=1+\lambda_{i}(1-\delta)$ for $i=1,2$. Then elaborating (3) with equality yields the following three cases:

1. $r_{1}>x_{1}>y_{1}: \delta x_{1}=y_{1}$.

2. $x_{1} \geq r_{1}>y_{1}: \delta x_{1}=\left(1+\lambda_{1}\right) y_{1}-\delta \lambda_{1} r_{1}$.

3. $x_{1}>y_{1} \geq r_{1}: \delta x_{1}=\mu_{1} y_{1}$.

These three cases are exhaustive - it is easy to check that the case $y_{1} \geq x_{1}$ cannot occur. From (2) we obtain three similar cases:

I. $r_{2}>y_{2}>x_{2}: \delta y_{2}=x_{2}$.

II. $y_{2} \geq r_{2}>x_{2}: \delta y_{2}=\left(1+\lambda_{2}\right) x_{2}-\delta \lambda_{2} r_{2}$.

III. $y_{2}>x_{2} \geq r_{2}: \delta y_{2}=\mu_{2} x_{2}$.

By combining these equations we obtain a partition of the unit square $[0,1]^{2}$ of all possible pairs of reference points $\left(r_{1}, r_{2}\right)$ into nine sets. These sets are accurately depicted in Figure 1 , and denoted by $X_{1, \mathrm{I}}, \ldots, X_{3, \mathrm{III}}$. Within one and the same set $X_{\text {., }}$. the equilibrium proposals of the players take the same form, which may or may not depend on the specific values of the reference points within the set.

A formal description of these nine sets and of all associated equilibrium proposals is given in Appendix A. Here we limit ourselves to the main aspects.

In the set $X_{1, \mathrm{I}}$ the reference points are relatively high and the classical Rubinstein proposals

$$
x^{1, \mathrm{I}}=\left(\frac{1}{1+\delta}, \frac{\delta}{1+\delta}\right), y^{1, \mathrm{I}}=\left(\frac{\delta}{1+\delta}, \frac{1}{1+\delta}\right) .
$$

obtain. These are independent of the values of the reference points.

Also in the sets $X_{1, \text { III }}$ and $X_{3, \mathrm{I}}$ the equilibrium proposals are constant and do not depend on the reference points. In $X_{3, \mathrm{III}}$, which is the relevant set for the equilibrium outcome in Theorem 3.1 below, the equilibrium proposals are

$$
x^{3, \mathrm{III}}=\left(\frac{\mu_{1}\left(\mu_{2}-\delta\right)}{\mu_{1} \mu_{2}-\delta^{2}}, \frac{\delta\left(\mu_{1}-\delta\right)}{\mu_{1} \mu_{2}-\delta^{2}}\right), y^{3, \mathrm{III}}=\left(\frac{\delta\left(\mu_{2}-\delta\right)}{\mu_{1} \mu_{2}-\delta^{2}}, \frac{\mu_{2}\left(\mu_{1}-\delta\right)}{\mu_{1} \mu_{2}-\delta^{2}}\right) .
$$

Again, these proposals do not depend directly on the reference points.

In $X_{1, \mathrm{II}}$ and $X_{3, \mathrm{II}}$ the equilibrium proposals depend explicitly on player 2's reference point but not on player 1's reference point; and in $X_{2, \mathrm{I}}$ and $X_{2 \text {,III }}$ the equilibrium proposals depend explicitly on player 1 's reference point but not 


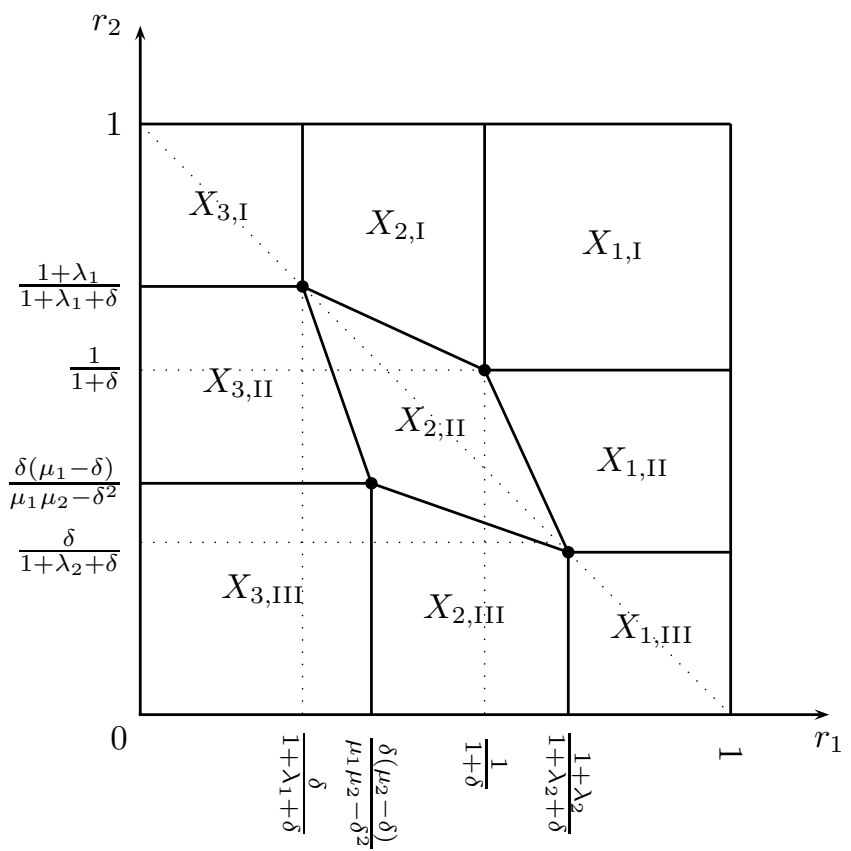

Figure 1: The partition $X_{1, \mathrm{I}}, \ldots, X_{3, \mathrm{III}}$.

on player 2's reference point. In $X_{2, \mathrm{II}}$ the proposals depend on both players' reference points. Thus, only intermediate valued reference points turn up in the equilibrium proposals explicitly. An equilibrium share is above the reference point if this is low, and below the reference point if this is high.

We now define strategies $\hat{f}$ for player 1 and $\hat{g}$ for player 2 based on the sets $X_{\omega}$ and associated proposals $x^{\omega}, y^{\omega}$, where $\omega \in\{1, \mathrm{I}, \ldots, 3$,III $\}$. Consider player 1 . At any odd moment $t$ and for any reference point $\left(r_{1}, r_{2}\right)$, take the (unique) $X_{\omega}$ containing $\left(r_{1}, r_{2}\right)$ : then player 1 makes the corresponding proposal $x^{\omega}$. At any even moment $t$ and for any reference point $\left(r_{1}, r_{2}\right)$, take again the relevant set $X_{\omega}$ : then player 1 accepts a proposal $z$ if and only if $z_{1} \geq y_{1}^{\omega}$. This defines the strategy $\hat{f}$. The strategy $\hat{g}$ for player 2 is defined similarly.

We now have the following result.

Theorem 3.1 The strategy profile $(\hat{f}, \hat{g})$ is an SPE. The outcome is

$$
x^{3, \mathrm{III}}=\left(\frac{\mu_{1}\left(\mu_{2}-\delta\right)}{\mu_{1} \mu_{2}-\delta^{2}}, \frac{\delta\left(\mu_{1}-\delta\right)}{\mu_{1} \mu_{2}-\delta^{2}}\right) .
$$

The proof of Theorem 3.1 is in Appendix A.

\section{A uniqueness result}

Let $(f, g)$ be a pair of strategies and consider the following possible conditions on $(f, g)$. 
(U1) $f$ and $g$ are stationary Markov strategies. Specifically, the proposal prescribed by $f$ at each odd moment is time independent and depends only on the reference points at that moment, and the $Y / N$ decision prescribed by $f$ at each even moment depends only on player 2's proposal and the reference points at that moment. Similarly for $g$.

(U2) Immediate acceptance. Any proposal made by player 1 according to $f$ is accepted by player 2 according to $g$, and conversely.

(U3) Accept-reject indifference. According to $(f, g)$, player 2 is indifferent between accepting $(\mathrm{Y})$ or rejecting $(\mathrm{N})$ a proposal made by player 1 , and conversely.

Note that these conditions are satisfied by the subgame perfect equilibrium in the classical model (without loss aversion). The equilibrium $(\hat{f}, \hat{g})$ in Theorem 3.1 was in fact constructed using these assumptions, which makes the following result intuitive.

Theorem $4.1(\hat{f}, \hat{g})$ is the unique SPE strategy profile satisfying (U1), (U2), and (U3).

The formal (lengthy) proof is presented in Appendix B. We now proceed with a discussion of these conditions.

The condition that the equilibrium strategies are stationary Markov strategies implies that they depend on the history of play of the game only through the effect this play has on the players' reference points. Note that this does not imply that the players are restricted to stationary Markov strategies: the SPE $(\hat{f}, \hat{g})$ is resistent to deviations also with other strategies.

The second condition means that any proposal is immediately accepted. We can in fact show that any SPE must satisfy this condition in some subgames, namely those where the reference points are higher than the (equilibrium) shares of the pie. This is intuitive, cf. the extreme case where the reference points are equal to 1 and, thus, are fixed throughout the rest of the game, so that such a subgame is equivalent to the classical game without loss aversion.

The third condition, finally, requires that each player is indifferent between accepting and rejecting the proposal made by the other player. Note that it follows from the basic equilibrium condition that accepting a proposal must make a player at least as well off as rejecting it. In the classical model with loss neutral players a player $j$ cannot be strictly better off since otherwise the proposing player $i$ could lower the share of $j$ in the proposal and, thus, increase his own share and be better off. This argument, however is based on the fact that in the classical model the payoffs of the players do not change as a result of playing the game. In our model we cannot exclude the possibility that such a deviation by the proposing player $i$ may lead to rejection by $j$ since $j$ 's new reference point resulting from the rejection may be lower as it would have been from rejecting the equilibrium proposal. This may effect not only player $j$ 's future payoff but also the play of the game after rejection. 
Based on many failed attempts to construct different equilibria we are inclined to think that the conditions (U1)-(U3) are implied by SPE, but, as mentioned, the question is still open.

\section{Analysis of the equilibrium}

In this section we analyze the $\operatorname{SPE}(\hat{f}, \hat{g})$ with respect to the loss aversion coefficients $\lambda_{1}$ and $\lambda_{2}$ and the probability of continuation $\delta$. We consider what happens if $\delta$ goes to 1 and if the players have different $\delta$ 's. We also consider what happens if the time lapse between proposals tends to zero, and establish a relation with asymmetric Nash bargaining solutions.

\subsection{Comparative statics of the loss aversion coefficients}

The result of playing the equilibrium $(\hat{f}, \hat{g})$ is the proposal and immediate acceptance of some distribution of the pie. Here we investigate the dependence of this distribution on the players' loss aversion coefficients. We restrict ourselves to the set of reference point pairs $X_{3, \mathrm{III}}$, since this is the relevant set at the beginning of the game. Moreover, the comparative statics results in subgames where the reference points are in different sets $X_{\omega}$, are similar. Recall that

$$
x^{3, \mathrm{III}}=\left(\frac{\mu_{1}\left(\mu_{2}-\delta\right)}{\mu_{1} \mu_{2}-\delta^{2}}, \frac{\delta\left(\mu_{1}-\delta\right)}{\mu_{1} \mu_{2}-\delta^{2}}\right)
$$

where $\mu_{i}=1+\lambda_{i}(1-\delta)$. It is sufficient to restrict the analysis to one player, because what one player gains is exactly what the other player loses. Differentiating with respect to $\lambda_{1}$ and $\lambda_{2}$ yields

$$
\frac{d x_{1}^{3, \text { III }}}{d \lambda_{1}}=-\frac{\delta^{2}(1-\delta)^{2}\left(1+\lambda_{2}\right)}{\left(\mu_{1} \mu_{2}-\delta^{2}\right)^{2}}<0
$$

and

$$
\frac{d x_{1}^{3, \text { III }}}{d \lambda_{2}}=\frac{\delta \mu_{1}(1-\delta)^{2}\left(1+\lambda_{1}\right)}{\left(\mu_{1} \mu_{2}-\delta^{2}\right)^{2}}>0 .
$$

Thus, players are hurt by their own loss aversion and benefit from their opponent's. This result also holds for the other subgames. However, if a player's reference point is very high, i.e., $r_{1} \geq x_{1}^{\omega}$ where $\omega \in\{1, \mathrm{I}, 1, \mathrm{II}, 1, \mathrm{III}\}$ or $r_{2} \geq y_{2}^{\omega}$ where $\omega \in\{3, \mathrm{I}, 2, \mathrm{I}, 1, \mathrm{I}\}$, then the equilibrium is independent of this player's degree of loss aversion. For instance, if $\left(r_{1}, r_{2}\right) \in X_{1, \mathrm{II}}$, then $\lambda_{1}$ has no influence on the equilibrium partition, but $\lambda_{2}$ has a positive effect on player 1's payoff and a negative effect on player 2's. 


\subsection{Convergence results with respect to the probability of continuation}

\subsubsection{Convergence of the SPE for a common $\delta$}

The question we consider here is what happens to the equilibrium if $\delta$ tends to one. Using l'Hôpital's rule we derive

$$
\lim _{\delta \rightarrow 1} x_{1}^{3, \text { III }}=\frac{1+\lambda_{2}}{2+\lambda_{1}+\lambda_{2}}
$$

and hence

$$
\lim _{\delta \rightarrow 1} x_{2}^{3, \text { III }}=\frac{1+\lambda_{1}}{2+\lambda_{1}+\lambda_{2}} .
$$

Observe that player $i$ 's payoff is conversely proportional to $1+\lambda_{j}$, where $i, j \in$ $\{1,2\}$ and $i \neq j$.

We can repeat this for all subgames. Figure 2 shows the nine sets of Figure 1 in the limit for $\delta$ going to 1 and the limit equilibrium proposals, for the case where $\lambda_{2}>\lambda_{1}$. The limit outcome in $X_{1, \mathrm{I}}$ is an equal split of the pie,

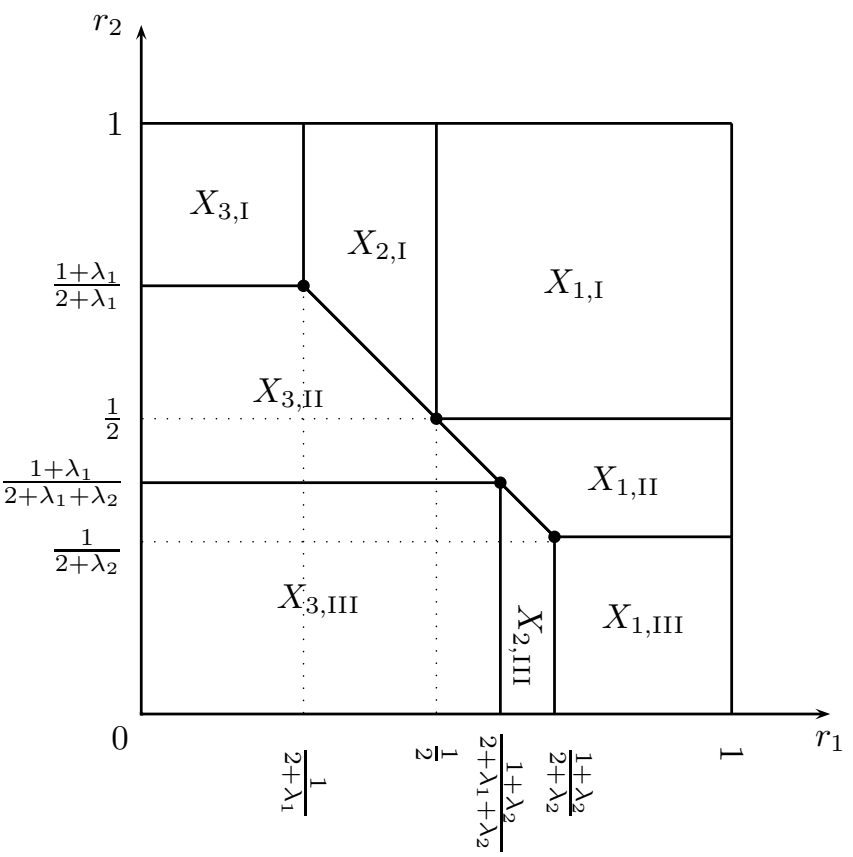

Figure 2: The equilibrium partitions for $\delta \rightarrow 1$, with $\lambda_{2}>\lambda_{1}$.

$(1 / 2,1 / 2)$. In $X_{3, \text { II }}$ and $X_{1, \text { II }}$ the limit equilibrium partition is $\left(1-r_{2}, r_{2}\right)$, while in $X_{2, \text { III }}$ and $X_{2, \mathrm{I}}$ it is $\left(r_{1}, 1-r_{1}\right)$. In $X_{3, \mathrm{I}}$ the limit equilibrium partition is $\left(1 /\left(2+\lambda_{1}\right),\left(1+\lambda_{1}\right) /\left(2+\lambda_{1}\right)\right)$, and in $X_{1, \text { III }}$ it is $\left(\left(1+\lambda_{2}\right) /\left(2+\lambda_{2}\right)\right.$, 
$\left.1 /\left(2+\lambda_{2}\right)\right)$. Set $X_{2, \text { II }}$ collapses to the line piece $r_{1}+r_{2}=1$ where $r_{1} \in$ $\left(1 /\left(2+\lambda_{1}\right),\left(1+\lambda_{2}\right) /\left(2+\lambda_{2}\right)\right)$. The limit equilibrium partition associated with this set is $\left(r_{1}, r_{2}\right)$.

\subsubsection{Convergence of the SPE for $\delta_{1} \neq \delta_{2}$}

We generalize the model to the situation where the players have individual continuation probabilities $\delta_{1}$ and $\delta_{2}$. In our setting, $\delta_{i}$ is interpreted as the probability that the game continues after player $i$ rejected $j$ 's proposal. Inequalities (2) and (3) generalize to

$$
\begin{aligned}
& \left(1+\lambda_{2}\right) x_{2}-\lambda_{2} \max \left\{r_{2}, x_{2}\right\} \geq \\
& \delta_{2}\left(\left(1+\lambda_{2}\right) y_{2}-\lambda_{2} \max \left\{y_{2}, \max \left\{r_{2}, x_{2}\right\}\right\}\right)-\left(1-\delta_{2}\right) \lambda_{2} \max \left\{r_{2}, x_{2}\right\}
\end{aligned}
$$

and

$$
\begin{aligned}
& \left(1+\lambda_{1}\right) y_{1}-\lambda_{1} \max \left\{r_{1}, y_{1}\right\} \geq \\
& \delta_{1}\left(\left(1+\lambda_{2}\right) y_{2}-\lambda_{2} \max \left\{y_{2}, \max \left\{r_{2}, x_{2}\right\}\right\}\right)-\left(1-\delta_{1}\right) \lambda_{2} \max \left\{r_{2}, x_{2}\right\} .
\end{aligned}
$$

All prior results also apply to this more general model. In particular, we obtain a solution to the above inequalities, considered as equalities, from which we construct a strategy profile. This strategy profile is the unique SPE satisfying (U1)-(U3).

A further generalization that leaves the previous results intact, is when there is a time lapse $\Delta$ between proposals, and the waiting time for breakdown of the game after player $i, i=1,2$, rejected the last proposal, is exponentially distributed with survival rate $\beta_{i}$. Then the probability that the game continues after player $i$ rejected a proposal is $\delta_{i}^{\Delta}$, where $\delta_{i}=\exp \left(-1 / \beta_{i}\right)$. Since the game starts with the reference points in $X_{3, \mathrm{III}}$, we limit the analysis to this case. The SPE outcome is

$$
\begin{aligned}
& x^{3, \text { III }}=\left(\frac{\mu_{1}\left(\mu_{2}-\delta_{2}^{\Delta}\right)}{\mu_{1} \mu_{2}-\delta_{1}^{\Delta} \delta_{2}^{\Delta}}, \frac{\delta_{2}^{\Delta}\left(\mu_{1}-\delta_{1}^{\Delta}\right)}{\mu_{1} \mu_{2}-\delta_{1}^{\Delta} \delta_{2}^{\Delta}}\right) \\
& y^{3, \text { III }}=\left(\frac{\delta_{1}^{\Delta}\left(\mu_{2}-\delta_{2}^{\Delta}\right)}{\mu_{1} \mu_{2}-\delta_{1}^{\Delta} \delta_{2}^{\Delta}}, \frac{\mu_{2}\left(\mu_{1}-\delta_{1}^{\Delta}\right)}{\mu_{1} \mu_{2}-\delta_{1}^{\Delta} \delta_{2}^{\Delta}}\right)
\end{aligned}
$$

where now $\mu_{i}:=1+\lambda_{i}\left(1-\delta_{i}^{\Delta}\right)$ for $i=1,2$. We can derive

$$
\lim _{\Delta \rightarrow 0} x^{3, \text { III }}=\left(\frac{\left(1+\lambda_{2}\right) \log \delta_{2}}{\left(1+\lambda_{1}\right) \log \delta_{1}+\left(1+\lambda_{2}\right) \log \delta_{2}}, \frac{\left(1+\lambda_{1}\right) \log \delta_{1}}{\left(1+\lambda_{1}\right) \log \delta_{1}+\left(1+\lambda_{2}\right) \log \delta_{2}}\right) .
$$

In a similar way we obtain

$$
\lim _{\Delta \rightarrow 0} y^{3, \mathrm{III}}=\lim _{\Delta \rightarrow 0} x^{3, \mathrm{III}} .
$$

Note that this is an asymmetric Nash bargaining solution as described by Harsanyi and Selten (1972) and Kalai (1977). That is, it is the solution to the optimization problem

$$
\arg \max _{z \in Z} z_{1}^{\alpha} z_{2}^{1-\alpha}
$$


where

$$
\alpha=\frac{\left(1+\lambda_{2}\right) \log \delta_{2}}{\left(1+\lambda_{1}\right) \log \delta_{1}+\left(1+\lambda_{2}\right) \log \delta_{2}} .
$$

In Appendix C, we extend this result to the situation where players have concave utility functions $v_{i}:[0,1] \rightarrow[0,1]$, and the feasible set associated with the partitions of the pie is

$$
\tilde{Z}:=\left\{\left(v_{1}(\gamma), v_{2}(1-\gamma)\right) \mid 0 \leq \gamma \leq 1\right\}
$$

We construct an SPE, resulting in an $x \in \tilde{Z}$, which is a function of $\delta_{1}^{\Delta}$ and $\delta_{2}^{\Delta}$. Using an argument from Binmore et al. (1986) we show that if $\Delta$ goes to zero, then the SPE outcome $x$ converges to $\tilde{z}^{N}$ where

$$
\tilde{z}^{N}:=\arg \max _{z \in \tilde{Z}} z_{1}^{\alpha} z_{2}^{1-\alpha},
$$

with $\alpha$ as defined by (4). Thus, increased loss aversion of a player results in increased 'bargaining power' of the opponent.

\section{Concluding Remarks}

In this paper we have investigated the effect of loss aversion in the strategic bargaining game of alternating offers introduced by Rubinstein (1982), by constructing a subgame perfect equilibrium in the extended model, and performing a comparative statics analysis on the outcome with respect to the bargainers' loss aversion coefficients. We find that being loss averse has a negative effect on a player's equilibrium share. We further find that the outcome of the bargaining procedure converges to an asymmetric Nash bargaining solution if the exogenous probability of breakdown goes to zero, such that higher loss aversion leads to higher bargaining power of the opponent.

This subgame perfect equilibrium is the unique SPE that shares three distinguishing features - stationary Markov strategies, immediate acceptance, and accept-reject indifference - with the unique SPE of Rubinstein. It is an open question whether uniqueness also holds without all or some of these conditions. 


\section{A The formal model and the SPE}

In this section we formally complete the description of the model and show that the constructed strategy profile $(\hat{f}, \hat{g})$ is an SPE (i.e., we prove Theorem 3.1).

\section{A.1 Formal model}

We divide $T=\mathbb{N}$ into $T_{\text {odd }}:=\{1,3, \ldots\}$ and $T_{\text {even }}:=\{2,4, \ldots\}$. We assume that players have full information about the history of play: at any time $t \in T$, they know all previous proposals, their own as well as those of the other player.

Define $h^{t}$, the history of the game at time $t \in T$, as a vector of players' proposals which have taken place before and at time $t$. Specifically, $h^{t}:=$ $\left(z^{1}, \ldots, z^{t}\right)$, where $z^{s} \in Z$ for all $s \leq t$. Furthermore, define $H^{t}$ as the set of all possible histories $h^{t}$ of the bargaining procedure at time $t \in T$. That is, $H^{t}:=\prod_{s=1}^{t} Z$. Furthermore, let $H^{0}:=\left\{h^{0}\right\}$, where $h^{0}$ is the empty history. Henceforth, the term 'history' is used to indicate non-empty histories.

The players' strategies are elements in $F$ or $G$ where $F$ is the set of infinite sequences of functions $\left(f^{t}\right)_{t \in T}$ where

$$
\begin{array}{ll}
\text { for } t=1: & f^{t} \in Z, \\
\text { for } t>1 \text { and } t \in T_{\text {odd }}: & f^{t}: H^{t-1} \rightarrow Z, \\
\text { for } t \in T_{\text {even }}: & f^{t}: H^{t} \rightarrow\{\mathrm{Y}, \mathrm{N}\},
\end{array}
$$

and $G$ the set of infinite sequences of functions $\left(g^{t}\right)_{t \in T}$ where

$$
\begin{array}{ll}
\text { for } t \in T_{\text {odd }}: & g^{t}: H^{t} \rightarrow\{\mathrm{Y}, \mathrm{N}\}, \\
\text { for } t \in T_{\text {even }}: & g^{t}: H^{t-1} \rightarrow Z .
\end{array}
$$

An agreement path $\left(h^{t}, a\right)$ is a history $h^{t} \in H^{t}$ ending in acceptance of the time $t$ proposal. The set

$$
A^{t}:=\left\{\left(h^{t}, a\right) \mid h^{t} \in H^{t}\right\}
$$

contains all time $t$ agreement paths. The set

$$
A:=\bigcup_{t \in T} A^{t}
$$

contains all histories ending in agreement. Similarly, we define a disagreement path $\left(h^{t}, d\right)$ as a history $h^{t} \in H^{t}$ ending in breakdown of the negotiations upon rejection of the time $t$ proposal. We define $D^{t}:=\left\{\left(h^{t}, d\right) \mid h^{t} \in H^{t}\right\}$ and $D:=\bigcup_{t \in T} D^{t}$. The set $C^{t}$ contains all objects of the form $\left(h^{t}, c\right)$, i.e. histories that do not end at time $t$. Finally, we define

$$
H^{\infty}:=\left\{\left(z^{1}, z^{2}, \ldots\right) \mid z^{t} \in Z \text { for all } t \in T\right\},
$$

and refer to elements of $H^{\infty}$ as infinite paths. Then

$$
\bar{H}:=H^{\infty} \cup A \cup D
$$


is the set containing all paths of the game. Observe that a strategy profile $(f, g) \in F \times G$ determines a specific play of the game or, equivalently, a set of paths in $\bar{H}$. In particular, if $(f, g)$ leads to agreement on a partition at time $t$, then the set of paths associated with that strategy profile contains $t-1$ paths in $D$ and one in $A$. If $(f, g)$ never induces an agreement, then this set contains a single path in $H^{\infty}$, and countably many in $D$.

We introduce the function $\xi_{i}: \bar{H} \backslash H^{\infty} \rightarrow[0,1]$ that specifies for each finite path in $\bar{H}$ the (physical) share of the pie bargainer $i$ obtains. Specifically, for all $h^{t} \in H, h^{t}=\left(z^{1}, \ldots, z^{t}\right)$, we have

$$
\begin{aligned}
& \xi_{i}\left(h^{t}, a\right):=z_{i}^{t}, \text { and } \\
& \xi_{i}\left(h^{t}, d\right):=0 .
\end{aligned}
$$

We define player $i$ 's utility function for (dis)agreement paths as

$$
u_{i}\left(h^{t}, a\right):=w\left(\xi_{i}\left(h^{t}, a\right), r_{i}\left(h^{t}\right), \lambda_{i}\right), u_{i}\left(h^{t}, d\right):=w\left(\xi_{i}\left(h^{t}, d\right), r_{i}\left(h^{t}\right), \lambda_{i}\right) .
$$

Furthermore, player $i$ 's utility evaluation of paths in $H^{\infty}$, i.e., perpetual disagreement, is defined as $-\lambda_{i}$. That is,

$$
u_{i}(h):=-\lambda_{i} \text { for all } h \in H^{\infty} .
$$

Finally, we define the expected utility function $U_{i}: F \times G \rightarrow \mathbb{R}$. Let $t \in T$ be the point in time up until which the history is known, and let players play the strategy profile $(f, g) \in F \times G$ from then on. Then we say they play $\left(f\left|h^{t}, g\right| h^{t}\right)$ at time $t+1$, and we denote by $U_{i}\left(f\left|h^{t}, g\right| h^{t}\right)$ player $i$ 's time $t$ expected utility from the strategy profile $(f, g) \in F \times G$. This can be exactly calculated, and is known to both players.

The strategy profile $(f, g)$ is a subgame perfect equilibrium (SPE) if for every $t \in T$ and every $h^{t} \in H^{t}$, we have

$$
\begin{aligned}
& U_{1}\left(f\left|h^{t}, g\right| h^{t}\right) \geq U_{1}\left(\tilde{f}\left|h^{t}, g\right| h^{t}\right) \text { for all } \tilde{f}, \text { and } \\
& U_{2}\left(f\left|h^{t}, g\right| h^{t}\right) \geq U_{2}\left(f\left|h^{t}, \tilde{g}\right| h^{t}\right) \text { for all } \tilde{g} .
\end{aligned}
$$

\section{A.2 Proof of Theorem 3.1}

We first formally describe the nine sets, also referred to as regions, and associated proposals on which the definition of $(\hat{f}, \hat{g})$ is based.

\section{A.2.1 Definition of $X_{\omega}$ and $x^{\omega}, y^{\omega}$}

\section{- Region 1,I}

$$
X_{1, \mathrm{I}}=\left\{\left(r_{1}, r_{2}\right) \in[0,1]^{2} \mid r_{1}>\frac{1}{1+\delta}, r_{2}>\frac{1}{1+\delta}\right\} .
$$


The equilibrium proposals in $X_{1, \mathrm{I}}$ are

$$
x^{1, \mathrm{I}}=\left(\frac{1}{1+\delta}, \frac{\delta}{1+\delta}\right), y^{1, \mathrm{I}}=\left(\frac{\delta}{1+\delta}, \frac{1}{1+\delta}\right) .
$$

[Thus, if both players' reference points lie above $1 /(1+\delta)$, then the regular Rubinstein outcomes are obtained. In Figure 1, the Rubinstein outcome is the South-West corner point of this set.]

\section{- Region 1,III}

$$
X_{1, \mathrm{III}}=\left\{\left(r_{1}, r_{2}\right) \in[0,1]^{2} \mid r_{1}>\frac{1+\lambda_{2}}{1+\lambda_{2}+\delta}, r_{2} \leq \frac{\delta}{1+\lambda_{2}+\delta}\right\} .
$$

The equilibrium proposals in $X_{1, \text { III }}$ are

$$
\begin{aligned}
x^{1, \mathrm{III}} & =\left(\frac{1+\lambda_{2}}{1+\lambda_{2}+\delta}, \frac{\delta}{1+\lambda_{2}+\delta}\right) \\
y^{1, \mathrm{III}} & =\left(\frac{\delta\left(1+\lambda_{2}\right)}{1+\lambda_{2}+\delta}, \frac{1+\lambda_{2}(1-\delta)}{1+\lambda_{2}+\delta}\right) .
\end{aligned}
$$

[Observe that this set is a square, and that its North-West corner point lies on the line $r_{1}+r_{2}=1$.]

\section{- Region 3,I}

$$
X_{3, \mathrm{I}}=\left\{\left(r_{1}, r_{2}\right) \in[0,1]^{2} \mid r_{1} \leq \frac{\delta}{1+\lambda_{1}+\delta}, r_{2}>\frac{1+\lambda_{1}}{1+\lambda_{1}+\delta}\right\} .
$$

This set is similar to $X_{1, \mathrm{III}}$, but with the roles of the players reversed. The equilibrium proposals are

$$
\begin{aligned}
& x^{3, \mathrm{I}}=\left(\frac{1+\lambda_{1}(1-\delta)}{1+\lambda_{1}+\delta}, \frac{\delta\left(1+\lambda_{1}\right)}{1+\lambda_{1}+\delta}\right) \\
& y^{3, \mathrm{I}}=\left(\frac{\delta}{1+\lambda_{1}+\delta}, \frac{1+\lambda_{1}}{1+\lambda_{1}+\delta}\right) .
\end{aligned}
$$

[This set is again a square, and its South-East corner point lies on the line $r_{1}+r_{2}=1$.]

\section{- Region 3,III}

$$
X_{3, \mathrm{III}}=\left\{\left(r_{1}, r_{2}\right) \in[0,1]^{2} \mid r_{1} \leq \frac{\delta\left(\mu_{2}-\delta\right)}{\mu_{1} \mu_{2}-\delta^{2}}, r_{2} \leq \frac{\delta\left(\mu_{1}-\delta\right)}{\mu_{1} \mu_{2}-\delta^{2}}\right\}
$$

The equilibrium proposals are

$$
x^{3, \text { III }}=\left(\frac{\mu_{1}\left(\mu_{2}-\delta\right)}{\mu_{1} \mu_{2}-\delta^{2}}, \frac{\delta\left(\mu_{1}-\delta\right)}{\mu_{1} \mu_{2}-\delta^{2}}\right), y^{3, \text { III }}=\left(\frac{\delta\left(\mu_{2}-\delta\right)}{\mu_{1} \mu_{2}-\delta^{2}}, \frac{\mu_{2}\left(\mu_{1}-\delta\right)}{\mu_{1} \mu_{2}-\delta^{2}}\right) .
$$




\section{- Region 1,II}

$X_{1, \mathrm{II}}=\left\{\left(r_{1}, r_{2}\right) \in[0,1]^{2} \mid r_{1}>\frac{\left(\mu_{2}-\delta\right)+\delta \lambda_{2}\left(1-r_{2}\right)}{\left(1+\lambda_{2}\right)-\delta^{2}}, \frac{\delta}{1+\lambda_{2}+\delta}<r_{2} \leq \frac{1}{1+\delta}\right\}$.

The equilibrium proposals are

$$
\begin{aligned}
& x^{1, \mathrm{II}}=\left(\frac{\left(\mu_{2}-\delta\right)+\delta \lambda_{2}\left(1-r_{2}\right)}{\left(1+\lambda_{2}\right)-\delta^{2}}, \frac{\left.\delta(1-\delta)+\delta \lambda_{2} r_{2}\right)}{\left(1+\lambda_{2}\right)-\delta^{2}}\right) \\
& y^{1, \mathrm{II}}=\left(\frac{\delta\left(\mu_{2}-\delta\right)+\delta^{2} \lambda_{2}\left(1-r_{2}\right)}{\left(1+\lambda_{2}\right)-\delta^{2}}, \frac{\left(\mu_{2}-\delta\right)+\delta^{2} \lambda_{2} r_{2}}{\left(1+\lambda_{2}\right)-\delta^{2}}\right) .
\end{aligned}
$$

[Observe that these proposals now depend on player 2's reference point.]

\section{- Region 3,II}

$$
\begin{gathered}
X_{3, \mathrm{II}}=\left\{\left(r_{1}, r_{2}\right) \in[0,1]^{2} \mid r_{1} \leq \frac{\delta\left(\mu_{2}-\delta+\delta \lambda_{2}\left(1-r_{2}\right)\right)}{\mu_{1}\left(1+\lambda_{2}\right)-\delta^{2}},\right. \\
\left.\frac{\delta\left(\mu_{1}-\delta\right)}{\mu_{1} \mu_{2}-\delta^{2}}<r_{2} \leq \frac{1+\lambda_{1}}{1+\lambda_{1}+\delta}\right\} .
\end{gathered}
$$

The equilibrium proposals are

$$
\begin{aligned}
& x^{3, \mathrm{II}}=\left(\frac{\mu_{1}\left(\mu_{2}-\delta+\lambda_{2} \delta\left(1-r_{2}\right)\right)}{\mu_{1}\left(1+\lambda_{2}\right)-\delta^{2}}, \frac{\delta\left(\mu_{1}-\delta+\lambda_{2} r_{2} \mu_{1}\right)}{\mu_{1}\left(1+\lambda_{2}\right)-\delta^{2}}\right) \\
& y^{3, \mathrm{II}}=\left(\frac{\delta\left(\mu_{2}-\delta+\delta \lambda_{2}\left(1-r_{2}\right)\right)}{\mu_{1}\left(1+\lambda_{2}\right)-\delta^{2}}, \frac{\left(\mu_{1}-\delta\right)\left(1+\lambda_{2}\right)+\delta^{2} \lambda_{2} r_{2}}{\mu_{1}\left(1+\lambda_{2}\right)-\delta^{2}}\right) .
\end{aligned}
$$

[In this set player 1's reference point is low, which explains that the equilibrium proposals do not depend on it.]

\section{- Region 2,I}

$X_{2, \mathrm{I}}=\left\{\left(r_{1}, r_{2}\right) \in[0,1]^{2} \mid \frac{\delta}{1+\lambda_{1}+\delta}<r_{1} \leq \frac{1}{1+\delta}, r_{2}>\frac{\left(\mu_{1}-\delta\right)+\delta \lambda_{1}\left(1-r_{1}\right)}{\left(1+\lambda_{1}\right)-\delta^{2}}\right\}$.

The equilibrium proposals are

$$
\begin{aligned}
& x^{2 . \mathrm{I}}=\left(\frac{\left(\mu_{1}-\delta\right)+\delta^{2} \lambda_{1} r_{1}}{\left(1+\lambda_{1}\right)-\delta^{2}}, \frac{\delta\left(\mu_{1}-\delta\right)+\delta^{2} \lambda_{1}\left(1-r_{1}\right)}{\left(1+\lambda_{1}\right)-\delta^{2}}\right) \\
& y^{2, \mathrm{I}}=\left(\frac{\left.\delta(1-\delta)+\delta \lambda_{1} r_{1}\right)}{\left(1+\lambda_{1}\right)-\delta^{2}}, \frac{\left(\mu_{1}-\delta\right)+\delta \lambda_{1}\left(1-r_{1}\right)}{\left(1+\lambda_{1}\right)-\delta^{2}}\right) .
\end{aligned}
$$

[This set is similar to $X_{1, \mathrm{II}}$.]

\section{- Region 2,III}

$$
X_{2, \mathrm{III}}=\left\{\left(r_{1}, r_{2}\right) \in[0,1]^{2} \mid \frac{\delta\left(\mu_{2}-\delta\right)}{\mu_{1} \mu_{2}-\delta^{2}} \leq r_{1} \leq \frac{1+\lambda_{2}}{1+\lambda_{2}+\delta},\right.
$$




$$
\left.r_{2} \leq \frac{\delta\left(\left(\mu_{1}-\delta\right)+\delta \lambda_{1}\left(1-r_{1}\right)\right)}{\left(1+\lambda_{1}\right) \mu_{2}-\delta^{2}}\right\}
$$

The equilibrium proposals are

$$
\begin{aligned}
& x^{2, \mathrm{III}}=\left(\frac{\left(1+\lambda_{1}\right)\left(\mu_{2}-\delta\right)+\delta^{2} \lambda_{1} r_{1}}{\left(1+\lambda_{1}\right) \mu_{2}-\delta^{2}}, \frac{\delta\left(\left(\mu_{1}-\delta\right)+\delta \lambda_{1}\left(1-r_{1}\right)\right)}{\left(1+\lambda_{1}\right) \mu_{2}-\delta^{2}}\right) \\
& y^{2, \mathrm{III}}=\left(\frac{\delta\left(\left(\mu_{2}-\delta\right)+\mu_{2} \lambda_{1} r_{1}\right)}{\left(1+\lambda_{1}\right) \mu_{2}-\delta^{2}}, \frac{\mu_{2}\left(\left(\mu_{1}-\delta\right)+\delta \lambda_{1}\left(1-r_{1}\right)\right)}{\left(1+\lambda_{1}\right) \mu_{2}-\delta^{2}}\right) .
\end{aligned}
$$

[In this set player 2's reference point is low, which explains that the equilibrium proposals do not depend on it.]

\section{- Region 2,II}

The boundaries of $X_{2, \text { II }}$ are described by the boundaries of the neighboring sets, see Figure 1 . The equilibrium proposals $x^{2, \mathrm{II}}$ and $y^{2, \mathrm{II}}$ are given by

$$
\begin{aligned}
& x_{1}^{2, \mathrm{II}}=\frac{\left(1+\lambda_{1}\right)\left(\left(\mu_{2}-\delta\right)+\delta \lambda_{2}\left(1-r_{2}\right)\right)+\delta^{2} \lambda_{1} r_{1}}{\left(1+\lambda_{1}\right)\left(1+\lambda_{2}\right)-\delta^{2}}, \\
& x_{2}^{2, \mathrm{II}}=\frac{\delta\left(\mu_{1}-\delta+\delta \lambda_{1}\left(1-r_{1}\right)+\lambda_{2}\left(1+\lambda_{1}\right) r_{2}\right)}{\left(1+\lambda_{1}\right)\left(1+\lambda_{2}\right)-\delta^{2}}, \\
& y_{1}^{2, \mathrm{II}}=\frac{\delta\left(\mu_{2}-\delta+\delta \lambda_{2}\left(1-r_{2}\right)+\lambda_{1}\left(1+\lambda_{2}\right) r_{1}\right)}{\left(1+\lambda_{1}\right)\left(1+\lambda_{2}\right)-\delta^{2}}, \\
& y_{2}^{2, \mathrm{II}}=\frac{\left(1+\lambda_{2}\right)\left(\left(\mu_{1}-\delta\right)+\delta \lambda_{1}\left(1-r_{1}\right)\right)+\delta^{2} \lambda_{2} r_{2}}{\left(1+\lambda_{1}\right)\left(1+\lambda_{2}\right)-\delta^{2}} .
\end{aligned}
$$

\section{A.2.2 Proof of Theorem 3.1}

To prove Theorem 3.1, we use the one-deviation property. The one-deviation property says that for a strategy profile $(f, g) \in F \times G$ to be a subgame perfect equilibrium it is sufficient that no player can improve by deviating only once, i.e., at one point in time.

Hendon et al. (1996) showed that the one-deviation property holds in infinitehorizon extensive-form games which are continuous at infinity ${ }^{3}$. Continuity at infinity is defined as follows. For any $\varepsilon>0$ there is a number $t \in T$ such that if two strategy profiles $(f, g),\left(f^{\prime}, g^{\prime}\right) \in F \times G$ are such that $\left(f^{s}, g^{s}\right)=\left(f^{\prime s}, g^{\prime s}\right)$ for all $s \leq t$, then $\left|U_{i}(f, g)-U_{i}\left(f^{\prime}, g^{\prime}\right)\right|<\varepsilon$.

Lemma A.1 The bargaining game with loss averse players is continuous at infinity.

Proof. Let $\varepsilon>0$, and let $(f, g)$ and $\left(f^{\prime}, g^{\prime}\right)$ be strategy profiles in $F \times G$ satisfying $\left(f^{s}, g^{s}\right)=\left(f^{\prime s}, g^{\prime s}\right)$ for all $s \leq t$, where $t>\max _{i=1,2} \log _{\delta} \varepsilon /\left(1+\lambda_{i}\right)$. Observe that the largest payoff difference between two such strategy profiles

\footnotetext{
${ }^{3}$ Another requirement concerns Bayesian updating, but this is automatically fulfilled since our game is one of perfect information.
} 
would emerge when the one yields player $i$ the whole pie at time $t+1$, while the other leads to perpetual disagreement. In the former case, player $i$ would obtain

$$
\bar{U}_{i}=\delta^{t}+(1-\delta) \sum_{s=1}^{t} \delta^{s-1} u_{i}\left(h^{s}, d\right),
$$

while in the latter he would obtain

$$
\underline{U}_{i}=(1-\delta) \sum_{s=1}^{\infty} \delta^{s-1} u_{i}\left(h^{s}, d\right) .
$$

From the fact that $u_{i}\left(h^{t}, d\right) \geq-\lambda_{i}$ for all $t \in T$, it follows that

$$
\begin{aligned}
\underline{U}_{i} & =(1-\delta) \sum_{s=1}^{t} \delta^{s-1} u_{i}\left(h^{s}, d\right)+(1-\delta) \sum_{s=t+1}^{\infty} \delta^{s-1} u_{i}\left(h^{s}, d\right) \\
& \geq(1-\delta) \sum_{s=1}^{t} \delta^{s-1} u_{i}\left(h^{s}, d\right)+\delta^{t}(1-\delta)\left(-\lambda_{i}\right) \frac{1}{1-\delta} \\
& =-\delta^{t} \lambda_{i}+(1-\delta) \sum_{s=1}^{t} \delta^{s-1} u_{i}\left(h^{s}, d\right) .
\end{aligned}
$$

From this and the fact that $\bar{U}_{i}-\underline{U}_{i} \geq 0$, we obtain

$$
\begin{array}{r}
\left|U_{i}(f, g)-U_{i}\left(f^{\prime}, g^{\prime}\right)\right| \leq \bar{U}_{i}-\underline{U}_{i} \leq \delta^{t}+(1-\delta) \sum_{s=1}^{t} \delta^{s-1} u_{i}\left(h^{s}, d\right) \\
+\delta^{t} \lambda_{i}-(1-\delta) \sum_{s=1}^{t} \delta^{s-1} u_{i}\left(h^{s}, d\right)=\delta^{t}\left(1+\lambda_{i}\right)<\varepsilon .
\end{array}
$$

Hence, the game is continuous at infinity.

It follows from Lemma A.1 that we can use the one-deviation property.

Denote $\Omega=\{1$. I., ...,3.III. $\}$.

Proof of Theorem 3.1. To show that $(\hat{f}, \hat{g})$ is SPE, it is sufficient to show that there is no subgame in which player 1 (2) can profitably deviate from $\hat{f}$ $(\hat{g})$ at a single time $t \in T$, given that player $2(1)$ plays strategy $\hat{g}(\hat{f})$. Assume player 2 plays strategy $\hat{g}$. We denote the utility player 1 obtains by following strategy $\hat{f}$ by $u_{1}^{*}$.

Let $h^{t-1} \in C^{t-1}$, i.e. $h^{t-1}$ is a history continuing to the next period. Assume $h^{t-1}$ is such that $\left(r_{1}\left(h^{t-1}\right), r_{2}\left(h^{t-1}\right)\right) \in X_{\omega}$ with $\omega \in \Omega$, and that $h^{t}=\left(h^{t-1}, z\right)$ with $z \in Z$. If $t$ is odd (even), then $z$ is proposed by player 1 (2). If the proposal $z$ is rejected, then the game continues with probability $\delta$ to the next period or ends with probability $1-\delta$. If the game continues to time $t+1$, then it ends 
in immediate acceptance of the proposal at $t+1$, since $(\hat{f}, \hat{g})$ is the prevalent strategy profile.

To show that $\hat{f}$ is a best reply to $\hat{g}$ we distinguish two cases, namely $t$ is odd and $t$ is even. For each case, we consider three subcases. The reference point pair $\left(r_{1}, r_{2}\right)$ is in $X_{\omega}$ where

Case 1. $\omega \in\{1, \mathrm{I}, 1, \mathrm{II}, 1, \mathrm{III}\}$. Then $r_{1}>x_{1}^{\omega}>y_{1}^{\omega}$, and $y_{1}^{\omega}=\delta x_{1}^{\omega}$.

Case 2. $\omega \in\{2, \mathrm{I}, 2$,II, 2,III $\}$. Then $x_{1}^{\omega} \geq r_{1}>y_{1}^{\omega}$, and $y_{1}^{\omega}=\frac{\delta\left(x_{1}^{\omega}+\lambda_{1} r_{1}\right)}{1+\lambda_{1}}$.

Case 3. $\omega \in\{3, \mathrm{I}, 3, \mathrm{II}, 3, \mathrm{III}\}$. Then $x_{1}^{\omega}>y_{1}^{\omega} \geq r_{1}$, and $y_{1}^{\omega}=\frac{\delta}{\mu_{1}} x_{1}^{\omega}$.

$t$ odd, case 1. We distinguish between the following cases:

- $z_{1}=x_{1}^{\omega}$ : In this case player 1 follows strategy $\hat{f}$. Player 2 accepts, so

$$
u_{1}^{*}=u_{1}\left(h^{t}, a\right)=\left(1+\lambda_{1}\right) x_{1}^{\omega}-\lambda_{1} \max \left\{r_{1}, x_{1}^{\omega}\right\}=\left(1+\lambda_{1}\right) x_{1}^{\omega}-\lambda_{1} r_{1} .
$$

- $z_{1}<x_{1}^{\omega}$ : Then $z_{2}>x_{2}^{\omega}$, so player 2 accepts. Player 1's payoff is $u_{1}\left(h^{t}, a\right)=$ $\left(1+\lambda_{1}\right) z_{1}-\lambda_{1} \max \left\{r_{1}, z_{1}\right\}$. Observe that $r_{1} \geq x_{1}^{\omega}>z_{1}$ implies that

$$
u_{1}\left(h^{t}, a\right)=\left(1+\lambda_{1}\right) z_{1}-\lambda_{1} r_{1} .
$$

Then $z_{1}<x_{1}^{\omega}$ implies $u_{1}\left(h^{t}, a\right)<u_{1}^{*}$. Hence, the proposal $z$ is not optimal.

- $z_{1}>x_{1}^{\omega}$ : Then $z_{2}<x_{2}^{\omega}$, so player 2 rejects and proposes $y^{\omega}$ if the game continues. Hence, player 1 obtains

$$
\begin{aligned}
& \delta u_{1}\left(h^{t+1}, a\right)+(1-\delta) u_{1}\left(h^{t}, d\right) \\
= & \delta\left(\left(1+\lambda_{1}\right) y_{1}^{\omega}-\lambda_{1} \max \left\{y_{1}^{\omega}, r_{1}\right\}\right)-(1-\delta) \lambda_{1} r_{1} \\
= & \left(1+\lambda_{1}\right) \delta y_{1}^{\omega}-\delta \lambda_{1} r_{1}-(1-\delta) \lambda_{1} r_{1} \\
= & \left(1+\lambda_{1}\right) \delta y_{1}^{\omega}-\lambda_{1} r_{1} .
\end{aligned}
$$

Since $x_{1}^{\omega}>\delta^{2} x_{1}^{\omega}=\delta y_{1}^{\omega}$, we have $\delta u_{1}\left(h^{t+1}, a\right)+(1-\delta) u_{1}\left(h^{t}, d\right)<u_{1}^{*}$. Thus, the proposal $z$ is not optimal.

$t$ odd, case 2. We distinguish between three cases:

- $z_{1}=x_{1}^{\omega}$ : In this case player 1 follows strategy $\hat{f}$. Player 2 accepts, so

$$
u_{1}^{*}=u_{1}\left(h^{t}, a\right)=\left(1+\lambda_{1}\right) x_{1}^{\omega}-\lambda_{1} \max \left\{x_{1}^{\omega}, r_{1}\right\}=x_{1}^{\omega} .
$$

- $z_{1}<x_{1}^{\omega}$ : Since then $z_{2}>x_{2}^{\omega}$, player 2 accepts. Player 1's payoff is $u_{1}\left(h^{t}, a\right)=$ $\left(1+\lambda_{1}\right) z_{1}-\lambda_{1} \max \left\{r_{1}, z_{1}\right\}$. From

$$
\left(1+\lambda_{1}\right) z_{1}-\lambda_{1} \max \left\{r_{1}, z_{1}\right\} \leq z_{1}<x_{1}^{\omega}=u_{1}^{*},
$$

it follows that the proposal $z$ is not optimal. 
- $z_{1}>x_{1}^{\omega}$ : Since then $z_{2}<x_{2}^{\omega}$, player 2 rejects, and proposes $y^{\omega}$ if the game continues. Hence, player 1 obtains

$$
\begin{aligned}
& \delta u_{1}\left(h^{t+1}, a\right)+(1-\delta) u_{1}\left(h^{t}, d\right) \\
= & \left(1+\lambda_{1}\right) \delta y_{1}^{\omega}-\delta \lambda_{1} \max \left\{y_{1}^{\omega}, r_{1}\right\}-(1-\delta) \lambda_{1} r_{1} \\
= & \left(1+\lambda_{1}\right) \delta y_{1}^{\omega}-\lambda_{1} r_{1} .
\end{aligned}
$$

From $y_{1}^{\omega}=\frac{\delta\left(x_{1}^{\omega}+\lambda_{1} r_{1}\right)}{1+\lambda_{1}}$ it follows that $\delta x_{1}^{\omega}=\left(1+\lambda_{1}\right) y_{1}^{\omega}-\delta \lambda_{1} r_{1}$. Therefore,

$$
u_{1}^{*}=x_{1}^{\omega}=\left(1+\lambda_{1}\right) \frac{1}{\delta} y_{1}^{\omega}-\lambda_{1} r_{1}>\left(1+\lambda_{1}\right) \delta y_{1}^{\omega}-\lambda_{1} r_{1} .
$$

Thus, the proposal $z$ is not optimal.

$t$ odd, case 3 . We distinguish between three cases:

- $z_{1}=x_{1}^{\omega}$ : In this case player 1 follows strategy $\hat{f}$. Player 2 accepts, so

$$
u_{1}^{*}=u_{1}\left(h^{t}, a\right)=\left(1+\lambda_{1}\right) x_{1}^{\omega}-\lambda_{1} \max \left\{x_{1}^{\omega}, r_{1}\right\}=x_{1}^{\omega} .
$$

- $z_{1}<x_{1}^{\omega}$ : Since then $z_{2}>x_{2}^{\omega}$, player 2 accepts. Player 1's payoff is $u_{1}\left(h^{t}, a\right)=$ $\left(1+\lambda_{1}\right) z_{1}-\lambda_{1} \max \left\{r_{1}, z_{1}\right\}$. From

$$
\left(1+\lambda_{1}\right) z_{1}-\lambda_{1} \max \left\{r_{1}, z_{1}\right\} \leq z_{1}<x_{1}^{\omega},
$$

it follows that $u_{1}^{*}>u_{1}\left(h^{t}, a\right)$. Thus, the proposal $z$ is not optimal.

- $z_{1}>x_{1}^{\omega}$ : Since $z_{2}<x_{2}^{\omega}$, player 2 rejects, and proposes $y^{\omega}$ if the game continues. Hence, player 1 obtains

$$
\begin{aligned}
& \delta u_{1}\left(h^{t+1}, a\right)+(1-\delta) u_{1}\left(h^{t}, d\right) \\
= & \left(1+\lambda_{1}\right) \delta y_{1}^{\omega}-\delta \lambda_{1} \max \left\{y_{1}^{\omega}, r_{1}\right\}-(1-\delta) \lambda_{1} r_{1} \\
= & \delta y_{1}^{\omega}-(1-\delta) \lambda_{1} r_{1} .
\end{aligned}
$$

Observe that

$$
u_{1}^{*}=x_{1}^{\omega}>y_{1}^{\omega}>\delta y_{1}^{\omega} \geq \delta y_{1}^{\omega}-(1-\delta) \lambda_{1} r_{1} .
$$

Hence, the proposal $z$ is not optimal.

$t$ even, case 1. Assume player 2 proposes some $z \in Z$. Accepting gives player 1

$$
u_{1}\left(h^{t}, a\right)=\left(1+\lambda_{1}\right) z_{1}-\lambda_{1} \max \left\{r_{1}, z_{1}\right\} .
$$

Rejecting makes his reference point switch to $\max \left\{r_{1}, z_{1}\right\}$; if the game continues, he proposes $x^{\omega}$, and player 2 accepts. Since $r_{1}>x_{1}^{\omega}$ and $y_{1}^{\omega}=\delta x_{1}^{\omega}$, we have

$$
\begin{aligned}
& \delta u_{1}\left(h^{t+1}, a\right)+(1-\delta) u_{1}\left(h^{t}, d\right) \\
= & \left(1+\lambda_{1}\right) \delta x_{1}^{\omega}-\delta \lambda_{1} \max \left\{x_{1}^{\omega}, \max \left\{r_{1}, z_{1}\right\}\right\}-(1-\delta) \lambda_{1} \max \left\{r_{1}, z_{1}\right\} \\
= & \left(1+\lambda_{1}\right) \delta x_{1}^{\omega}-\delta \lambda_{1} \max \left\{r_{1}, z_{1}\right\}-(1-\delta) \lambda_{1} \max \left\{r_{1}, z_{1}\right\} \\
= & \left(1+\lambda_{1}\right) y_{1}^{\omega}-\lambda_{1} \max \left\{r_{1}, z_{1}\right\} .
\end{aligned}
$$


Hence, it is optimal to accept the proposal $z$ if $z_{1} \geq y_{1}^{\omega}$, and to reject it otherwise. That is, to play strategy $\hat{f}$.

$t$ even, case 2. Assume player 2 proposes some $z \in Z$ with $z_{1} \leq x_{1}^{\omega^{\prime}}$ where $\omega^{\prime} \in\{1, \mathrm{I}, 1, \mathrm{II}, 1, \mathrm{III}\}$. Accepting gives player 1

$$
u_{1}\left(h^{t}, a\right)=\left(1+\lambda_{1}\right) z_{1}-\lambda_{1} \max \left\{r_{1}, z_{1}\right\} .
$$

If he rejects and the game continues, then the reference point $r_{1}\left(h^{t}\right)$ is $\max \left\{r_{1}, z_{1}\right\}$. Thus, at $t+1$ we enter a new game in which $\left(\max \left\{r_{1}, z_{1}\right\}, r_{2}\right)$ is the prevalent reference point pair. Since $\left(\max \left\{r_{1}, z_{1}\right\}, r_{2}\right) \in \omega$ where $\omega \in\{2, \mathrm{I}, 2$,II, 2,III $\}$, we have $x_{1}^{\omega} \geq \max \left\{r_{1}, z_{1}\right\} \geq y_{1}^{\omega}$, where $y_{1}^{\omega}=\delta\left(x_{1}^{\omega}+\lambda_{1} \max \left\{r_{1}, z_{1}\right\}\right) /\left(1+\lambda_{1}\right)$. At $t+1$ player 1 proposes $x_{1}^{\omega}$ and player 2 accepts, so rejecting $z$ yields

$$
\begin{aligned}
& \delta u_{1}\left(h^{t+1}, a\right)+(1-\delta) u_{1}\left(h^{t}, d\right) \\
= & \left(1+\lambda_{1}\right) \delta x_{1}^{\omega}-\delta \lambda_{1} \max \left\{x_{1}^{\omega}, \max \left\{r_{1}, z_{1}\right\}\right\}-(1-\delta) \lambda_{1} \max \left\{r_{1}, z_{1}\right\} \\
= & \delta x_{1}^{\omega}-(1-\delta) \lambda_{1} \max \left\{r_{1}, z_{1}\right\} \\
= & \left(1+\lambda_{1}\right) y_{1}^{\omega}-\lambda_{1} \max \left\{r_{1}, z_{1}\right\} .
\end{aligned}
$$

If player 2 proposes $z \in Z$ with $z_{1}>x_{1}^{\omega^{\prime}}$, then accepting yields $u_{1}\left(h^{t}, a\right)=z_{1}$ and rejecting

$$
\begin{aligned}
& \delta u_{1}\left(h^{t+1}, a\right)+(1-\delta) u_{1}\left(h^{t}, d\right) \\
= & \left(1+\lambda_{1}\right) \delta x_{1}^{\omega^{\prime}}-\delta \lambda_{1} \max \left\{x_{1}^{\omega^{\prime}}, \max \left\{r_{1}, z_{1}\right\}\right\}-(1-\delta) \lambda_{1} \max \left\{r_{1}, z_{1}\right\} \\
= & \left(1+\lambda_{1}\right) y_{1}^{\omega^{\prime}}-\lambda_{1} z_{1} .
\end{aligned}
$$

Since $z_{1}>x_{1}^{\omega^{\prime}}>y_{1}^{\omega^{\prime}}$, we have $u_{1}\left(h^{t}, a\right)>\delta u_{1}\left(h^{t+1}, a\right)+(1-\delta) u_{1}\left(h^{t}, d\right)$. In general, it is optimal to accept the proposal $z$ if $z_{1} \geq y_{1}^{\omega}$, and to reject it otherwise. That is, it is optimal to follow strategy $\hat{f}$.

$t$ even, case 3. Assume player 2 proposes some $z \in Z$ with $z_{1}<y_{1}^{\omega}$. Note that $r_{1}<x_{1}^{\omega}$. Hence, rejecting yields

$$
\begin{aligned}
& \delta u_{1}\left(h^{t+1}, a\right)+(1-\delta) u_{1}\left(h^{t}, d\right) \\
= & \left(1+\lambda_{1}\right) \delta x_{1}^{\omega}-\delta \lambda_{1} \max \left\{x_{1}^{\omega}, \max \left\{r_{1}, z_{1}\right\}\right\}-(1-\delta) \lambda_{1} \max \left\{r_{1}, z_{1}\right\} \\
= & \delta x_{1}^{\omega}-(1-\delta) \lambda_{1} \max \left\{r_{1}, z_{1}\right\} .
\end{aligned}
$$

Accepting yields $u_{1}\left(h^{t}, a\right)=\left(1+\lambda_{1}\right) z_{1}-\lambda_{1} \max \left\{r_{1}, z_{1}\right\}$. Since $y_{1}^{\omega}=\frac{\delta}{\mu_{1}} x_{1}^{\omega}$, we have

$$
\begin{aligned}
u_{1}\left(h^{t}, a\right) & =\left(1+\lambda_{1}\right) z_{1}-\lambda_{1} \max \left\{r_{1}, z_{1}\right\} \\
& =\left(1+\lambda_{1}\right) z_{1}-\delta \lambda_{1} \max \left\{r_{1}, z_{1}\right\}-(1-\delta) \lambda_{1} \max \left\{r_{1}, z_{1}\right\} \\
& <\left(1+\lambda_{1}\right) y_{1}^{\omega}-\delta \lambda_{1} \max \left\{r_{1}, y_{1}^{\omega}\right\}-(1-\delta) \lambda_{1} \max \left\{r_{1}, z_{1}\right\} \\
& =\left(1+\lambda_{1}\right) y_{1}^{\omega}-\delta \lambda_{1} y_{1}^{\omega}-(1-\delta) \lambda_{1} \max \left\{r_{1}, z_{1}\right\} \\
& =\mu_{1} y_{1}^{\omega}-(1-\delta) \lambda_{1} \max \left\{r_{1}, z_{1}\right\} \\
& =\delta x_{1}^{\omega}-(1-\delta) \lambda_{1} \max \left\{r_{1}, z_{1}\right\} .
\end{aligned}
$$


Thus, it is optimal to reject $z$. If player 2 proposes $z \in Z$ with $z_{1} \geq y_{1}^{\omega}$, then accepting yields

$$
u_{1}\left(h^{t}, a\right)=\left(1+\lambda_{1}\right) z_{1}-\lambda_{1} \max \left\{r_{1}, z_{1}\right\}=z_{1} .
$$

Let $z_{1} \leq y_{1}^{\omega^{\prime}}$ where $\omega^{\prime} \in\{1, \mathrm{I}, 1, \mathrm{II}, 1, \mathrm{III}\}$. If player 1 rejects and the game continues, then $r_{1}\left(h^{t}\right)=z_{1}$, and $\left(z_{1}, r_{2}\right) \in \omega^{\prime \prime}$ where $\omega^{\prime \prime} \in\{2, \mathrm{I}, 2, \mathrm{II}, 2, \mathrm{III}\}$. Note that then $y_{1}^{\omega^{\prime \prime}} \leq z_{1} \leq x_{1}^{\omega^{\prime \prime}}$. Thus, rejecting yields

$$
\begin{aligned}
& \delta u_{1}\left(h^{t+1}, a\right)+(1-\delta) u_{1}\left(h^{t}, d\right) \\
= & \left(1+\lambda_{1}\right) \delta x_{1}^{\omega^{\prime \prime}}-\delta \lambda_{1} \max \left\{x_{1}^{\omega^{\prime \prime}}, z_{1}\right\}-(1-\delta) \lambda_{1} z_{1} \\
= & \delta x_{1}^{\omega^{\prime \prime}}-(1-\delta) \lambda_{1} z_{1} \\
= & \left(1+\lambda_{1}\right) y_{1}^{\omega^{\prime \prime}}-\lambda_{1} z_{1} .
\end{aligned}
$$

Since $z_{1} \geq y_{1}^{\omega^{\prime \prime}}$, also $z_{1} \geq\left(1+\lambda_{1}\right) y_{1}^{\omega^{\prime \prime}}-\lambda_{1} z_{1}$. If player 2 proposes $z \in Z$ with $z_{1}>x_{1}^{\omega^{\prime}}$, then rejecting yields

$$
\begin{aligned}
& \delta u_{1}\left(h^{t+1}, a\right)+(1-\delta) u_{1}\left(h^{t}, d\right) \\
= & \left(1+\lambda_{1}\right) \delta x_{1}^{\omega^{\prime}}-\delta \lambda_{1} \max \left\{x_{1}^{\omega^{\prime}}, \max \left\{r_{1}, z_{1}\right\}\right\}-(1-\delta) \lambda_{1} \max \left\{r_{1}, z_{1}\right\} \\
= & \left(1+\lambda_{1}\right) \delta x_{1}^{\omega^{\prime}}-\delta \lambda_{1} z_{1}-(1-\delta) \lambda_{1} z_{1} \\
= & \left(1+\lambda_{1}\right) \delta x_{1}^{\omega^{\prime}}-\lambda_{1} z_{1} .
\end{aligned}
$$

Observe that $z_{1}>x_{1}^{\omega^{\prime}}$ implies $z_{1}>\delta x_{1}^{\omega^{\prime}}$. It follows that $z_{1}>\left(1+\lambda_{1}\right) \delta x_{1}^{\omega^{\prime}}-\lambda_{1} z_{1}$, i.e. accepting $z$ is optimal.

Thus, we have shown that player 1 can not profitably deviate from $\hat{f}$ at any single time $t$, given that player 2 plays strategy $\hat{g}$. The proof that player 2 can not profitably deviate from $\hat{g}$ at any single time $t$, given that player 1 plays $\hat{f}$, is analogous. Lemma A.1 implies that $(\hat{f}, \hat{g})$ is an SPE. 


\section{B Proof of Theorem 4.1}

Throughout this section, we assume that conditions (U1)-(U3) are satisfied.

\section{B.1 Preliminary lemmas}

Define a bargaining round as an offer made by player 1 and a counter offer made by player 2. Bargaining rounds are indexed with $i \in\{0,1,2, \ldots\}$. Then $\left(r_{1}^{i}, r_{2}^{i}\right)$ is the reference point pair prevalent at the beginning of bargaining round $i$. In view of (U1) it makes sense to define

$$
r_{1}^{i+1}:=\max \left\{r_{1}^{i}, y_{1}\left(r_{1}^{i}, r_{2}^{i+1}\right)\right\}, \text { and } r_{2}^{i+1}:=\max \left\{r_{2}^{i}, x_{2}\left(r_{1}^{i}, r_{2}^{i}\right)\right\} .
$$

This allows us to show the following.

Lemma B.1 When $x\left(r_{1}^{i}, r_{2}^{i}\right)$ is player 1's SPE proposal and $y\left(r_{1}^{i}, r_{2}^{i+1}\right)$ player 2's counterproposal, we have

$$
x_{2}\left(r_{1}^{i}, r_{2}^{i}\right)= \begin{cases}\delta-\delta y_{1}\left(r_{1}^{i}, r_{2}^{i+1}\right) & \text { if } r_{2}^{i}>y_{2}\left(r_{1}^{i}, r_{2}^{i+1}\right)>x_{2}\left(r_{1}^{i}, r_{2}^{i}\right) \\ \frac{\delta\left(1+\lambda_{2} r_{2}^{i+1}\right)}{1+\lambda_{2}}-\frac{\delta y_{1}\left(r_{1}^{i}, r_{2}^{i+1}\right)}{1+\lambda_{2}} & \text { if } y_{2}\left(r_{1}^{i}, r_{2}^{i+1}\right) \geq r_{2}^{i}>x_{2}\left(r_{1}^{i}, r_{2}^{i}\right) \\ \frac{\delta}{\mu_{2}}-\frac{\delta}{\mu_{2}} y_{1}\left(r_{1}^{i}, r_{2}^{i+1}\right) & \text { if } y_{2}\left(r_{1}^{i}, r_{2}^{i+1}\right)>x_{2}\left(r_{1}^{i}, r_{2}^{i}\right) \geq r_{2}^{i},\end{cases}
$$

and

$$
y_{1}\left(r_{1}^{i}, r_{2}^{i+1}\right)= \begin{cases}\delta-\delta x_{2}\left(r_{1}^{i+1}, r_{2}^{i+1}\right) & \text { if } r_{1}^{i}>x_{1}\left(r_{1}^{i+1}, r_{2}^{i+1}\right)>y_{1}\left(r_{1}^{i}, r_{2}^{i+1}\right) \\ \frac{\delta\left(1+\lambda_{1} r_{1}^{i+1}\right)}{1+\lambda_{1}}-\frac{\delta x_{2}\left(r_{1}^{i+1}, r_{2}^{i+1}\right)}{1+\lambda_{1}} & \text { if } x_{1}\left(r_{1}^{i+1}, r_{2}^{i+1}\right) \geq r_{1}^{i}>y_{1}\left(r_{1}^{i}, r_{2}^{i+1}\right) \\ \frac{\delta}{\mu_{1}}-\frac{\delta}{\mu_{1}} x_{2}\left(r_{1}^{i+1}, r_{2}^{i+1}\right) & \text { if } x_{1}\left(r_{1}^{i+1}, r_{2}^{i+1}\right)>y_{1}\left(r_{1}^{i}, r_{2}^{i+1}\right) \geq r_{1}^{i} .\end{cases}
$$

Proof. This follows from (U2) and (U3), and the definition of the players' utility functions.

For each $\omega \in \Omega$ we introduce the following sets $P_{\omega}$ and $Q_{\omega}$ of pairs of reference points:

$$
\begin{aligned}
& P_{1, \mathrm{I}}:=\left\{\left(r_{1}^{i}, r_{2}^{i}\right) \mid r_{2}^{i}>y_{2}\left(r_{1}^{i}, r_{2}^{i+1}\right), r_{1}^{i}>x_{1}\left(r_{1}^{i+1}, r_{2}^{i+1}\right)\right\} \\
& P_{2, \mathrm{I}}:=\left\{\left(r_{1}^{i}, r_{2}^{i}\right) \mid r_{2}^{i}>y_{2}\left(r_{1}^{i}, r_{2}^{i+1}\right), x_{1}\left(r_{1}^{i+1}, r_{2}^{i+1}\right) \geq r_{1}^{i}>y_{1}\left(r_{1}^{i}, r_{2}^{i+1}\right)\right\} \\
& P_{3, \mathrm{I}}:=\left\{\left(r_{1}^{i}, r_{2}^{i}\right) \mid r_{2}^{i}>y_{2}\left(r_{1}^{i}, r_{2}^{i+1}\right), y_{1}\left(r_{1}^{i}, r_{2}^{i+1}\right) \geq r_{1}^{i}\right\} \\
& P_{1, \mathrm{II}}:=\left\{\left(r_{1}^{i}, r_{2}^{i}\right) \mid y_{2}\left(r_{1}^{i}, r_{2}^{i+1}\right) \geq r_{2}^{i}>x_{2}\left(r_{1}^{i}, r_{2}^{i}\right), r_{1}^{i}>x_{1}\left(r_{1}^{i+1}, r_{2}^{i+1}\right)\right\} \\
& P_{2, \mathrm{II}}:=\left\{\left(r_{1}^{i}, r_{2}^{i}\right) \mid y_{2}\left(r_{1}^{i}, r_{2}^{i+1}\right) \geq r_{2}^{i}>x_{2}\left(r_{1}^{i}, r_{2}^{i}\right), x_{1}\left(r_{1}^{i+1}, r_{2}^{i+1}\right) \geq r_{1}^{i}>y_{1}\left(r_{1}^{i}, r_{2}^{i+1}\right)\right\}
\end{aligned}
$$




$$
\begin{aligned}
& P_{3, \mathrm{II}}:=\left\{\left(r_{1}^{i}, r_{2}^{i}\right) \mid y_{2}\left(r_{1}^{i}, r_{2}^{i+1}\right) \geq r_{2}^{i}>x_{2}\left(r_{1}^{i}, r_{2}^{i}\right), y_{1}\left(r_{1}^{i}, r_{2}^{i+1}\right) \geq r_{1}^{i}\right\} \\
& P_{1, \mathrm{III}}:=\left\{\left(r_{1}^{i}, r_{2}^{i}\right) \mid x_{2}\left(r_{1}^{i}, r_{2}^{i}\right) \geq r_{2}^{i}, r_{1}^{i}>x_{1}\left(r_{1}^{i+1}, r_{2}^{i+1}\right)\right\} \\
& P_{2, \mathrm{III}}:=\left\{\left(r_{1}^{i}, r_{2}^{i}\right) \mid x_{2}\left(r_{1}^{i}, r_{2}^{i}\right) \geq r_{2}^{i}, x_{1}\left(r_{1}^{i+1}, r_{2}^{i+1}\right) \geq r_{1}^{i}>y_{1}\left(r_{1}^{i}, r_{2}^{i+1}\right)\right\} \\
& P_{3, \mathrm{III}}:=\left\{\left(r_{1}^{i}, r_{2}^{i}\right) \mid x_{2}\left(r_{1}^{i}, r_{2}^{i}\right) \geq r_{2}^{i}, y_{1}\left(r_{1}^{i}, r_{2}^{i+1}\right) \geq r_{1}^{i}\right\} \\
& Q_{1, \mathrm{I}}:=\left\{\left(r_{1}^{i}, r_{2}^{i+1}\right) \mid r_{1}^{i}>x_{1}\left(r_{1}^{i+1}, r_{2}^{i+1}\right), r_{2}^{i+1}>y_{2}\left(r_{1}^{i+1}, r_{2}^{i+2}\right)\right\} \\
& Q_{1, \mathrm{II}}:=\left\{\left(r_{1}^{i}, r_{2}^{i+1}\right) \mid r_{1}^{i}>x_{1}\left(r_{1}^{i+1}, r_{2}^{i+1}\right), y_{2}\left(r_{1}^{i+1}, r_{2}^{i+2}\right) \geq r_{2}^{i+1}>x_{2}\left(r_{1}^{i+1}, r_{2}^{i+1}\right)\right\} \\
& Q_{1, \mathrm{III}}:=\left\{\left(r_{1}^{i}, r_{2}^{i+1}\right) \mid r_{1}^{i}>x_{1}\left(r_{1}^{i+1}, r_{2}^{i+1}\right), x_{2}\left(r_{1}^{i+1}, r_{2}^{i+1}\right) \geq r_{2}^{i+1}\right\} \\
& Q_{2, \mathrm{I}}:=\left\{\left(r_{1}^{i}, r_{2}^{i+1}\right) \mid x_{1}\left(r_{1}^{i+1}, r_{2}^{i+1}\right) \geq r_{1}^{i}>y_{1}\left(r_{1}^{i}, r_{2}^{i+1}\right), r_{2}^{i+1}>y_{2}\left(r_{1}^{i+1}, r_{2}^{i+2}\right)\right\} \\
& Q_{2, \mathrm{II}}:=\left\{\left(r_{1}^{i}, r_{2}^{i+1}\right) \mid x_{1}\left(r_{1}^{i+1}, r_{2}^{i+1}\right) \geq r_{1}^{i}>y_{1}\left(r_{1}^{i}, r_{2}^{i+1}\right), y_{2}\left(r_{1}^{i+1}, r_{2}^{i+2}\right) \geq r_{2}^{i+1}>\right. \\
&\left.x_{2}\left(r_{1}^{i+1}, r_{2}^{i+1}\right)\right\} \\
& Q_{2, \mathrm{III}}:=\left\{\left(r_{1}^{i}, r_{2}^{i+1}\right) \mid x_{1}\left(r_{1}^{i+1}, r_{2}^{i+1}\right) \geq r_{1}^{i}>y_{1}\left(r_{1}^{i}, r_{2}^{i+1}\right), x_{2}\left(r_{1}^{i+1}, r_{2}^{i+1}\right) \geq r_{2}^{i+1}\right\} \\
& Q_{3, \mathrm{I}}:=\left\{\left(r_{1}^{i}, r_{2}^{i+1}\right) \mid y_{1}\left(r_{1}^{i}, r_{2}^{i+1}\right) \geq r_{1}^{i}, r_{2}^{i+1}>y_{2}\left(r_{1}^{i+1}, r_{2}^{i+2}\right)\right\} \\
& Q_{3, \mathrm{II}}:=\left\{\left(r_{1}^{i}, r_{2}^{i+1}\right) \mid y_{1}\left(r_{1}^{i}, r_{2}^{i+1}\right) \geq r_{1}^{i}, y_{2}\left(r_{1}^{i+1}, r_{2}^{i+2}\right) \geq r_{2}^{i+1}>x_{2}\left(r_{1}^{i+1}, r_{2}^{i+1}\right)\right\} \\
& Q_{3, \mathrm{III}}:=\left\{\left(r_{1}^{i}, r_{2}^{i+1}\right) \mid y_{1}\left(r_{1}^{i}, r_{2}^{i+1}\right) \geq r_{1}^{i}, x_{2}\left(r_{1}^{i+1}, r_{2}^{i+1}\right) \geq r_{2}^{i+1}\right\} .
\end{aligned}
$$

We derive a series of lemmas for reference point pairs in these sets.

Lemma B.2 For all $\left(r_{1}^{i}, r_{2}^{i}\right) \in P_{\omega}$, we have

$$
x_{2}\left(r_{1}^{i}, r_{2}^{i}\right) \geq x_{2}\left(r_{1}^{i+1}, r_{2}^{i+1}\right) \Leftrightarrow x_{2}\left(r_{1}^{i}, r_{2}^{i}\right) \leq x_{2}^{\omega} .
$$

Similarly, for all $\left(r_{1}^{i}, r_{2}^{i+1}\right) \in Q_{\omega}$, we have

$$
y_{1}\left(r_{1}^{i}, r_{2}^{i+1}\right) \geq y_{1}\left(r_{1}^{i+1}, r_{2}^{i+2}\right) \Leftrightarrow y_{1}\left(r_{1}^{i}, r_{2}^{i+1}\right) \leq y_{1}^{\omega} .
$$

Proof. Let $\omega=1$,I and $\left(r_{1}^{i}, r_{2}^{i}\right) \in P_{\omega}$. By definition of $P_{1, \mathrm{I}}$ we have

$$
r_{2}^{i}>y_{2}\left(r_{1}^{i}, r_{2}^{i+1}\right) \text { and } r_{1}^{i}>x_{1}\left(r_{1}^{i+1}, r_{2}^{i+1}\right) .
$$

From Lemma B.1 we obtain

$$
\begin{aligned}
x_{2}\left(r_{1}^{i}, r_{2}^{i}\right) & =\delta-\delta y_{1}\left(r_{1}^{i}, r_{2}^{i+1}\right) \\
& =\delta-\delta\left(\delta-\delta x_{2}\left(r_{1}^{i+1}, r_{2}^{i+1}\right)\right) \\
& =\delta-\delta^{2}+\delta^{2} x_{2}\left(r_{1}^{i+1}, r_{2}^{i+1}\right) .
\end{aligned}
$$


Suppose $x_{2}\left(r_{1}^{i+1}, r_{2}^{i+1}\right) \geq x_{2}\left(r_{1}^{i}, r_{2}^{i}\right)$. Then by (10)

$$
x_{2}\left(r_{1}^{i}, r_{2}^{i}\right)=\delta-\delta^{2}+\delta^{2} x_{2}\left(r_{1}^{i+1}, r_{2}^{i+1}\right) \geq \delta-\delta^{2}+\delta^{2} x_{2}\left(r_{1}^{i}, r_{2}^{i}\right) .
$$

It follows that

$$
x_{2}\left(r_{1}^{i}, r_{2}^{i}\right) \geq \frac{\delta-\delta^{2}}{1-\delta^{2}}=\frac{\delta}{1+\delta}=x_{2}^{1, \mathrm{I}} .
$$

Suppose $x_{2}\left(r_{1}^{i+1}, r_{2}^{i+1}\right)<x_{2}\left(r_{1}^{i}, r_{2}^{i}\right)$. Then by (10)

$$
x_{2}\left(r_{1}^{i}, r_{2}^{i}\right)=\delta-\delta^{2}+\delta^{2} x_{2}\left(r_{1}^{i+1}, r_{2}^{i+1}\right)<\delta-\delta^{2}+\delta^{2} x_{2}\left(r_{1}^{i}, r_{2}^{i}\right),
$$

implying $x_{2}\left(r_{1}^{i}, r_{2}^{i}\right)<x_{2}^{1, \mathrm{I}}$. Therefore,

$$
x_{2}\left(r_{1}^{i}, r_{2}^{i}\right) \geq x_{2}\left(r_{1}^{i+1}, r_{2}^{i+1}\right) \Leftrightarrow x_{2}\left(r_{1}^{i}, r_{2}^{i}\right) \leq x_{2}^{1, \mathrm{I}} .
$$

Similarly, let $\omega=1, \mathrm{I}$ and $\left(r_{1}^{i}, r_{2}^{i+1}\right) \in Q_{\omega}$. By definition of $Q_{1, \mathrm{I}}$

$$
r_{1}^{i}>x_{1}\left(r_{1}^{i+1}, r_{2}^{i+1}\right) \text { and } r_{2}^{i+1}>y_{2}\left(r_{1}^{i+1}, r_{2}^{i+2}\right) .
$$

Then by Lemma B.1

$$
\begin{aligned}
y_{1}\left(r_{1}^{i}, r_{2}^{i+1}\right) & =\delta-\delta x_{2}\left(r_{1}^{i+1}, r_{2}^{i+1}\right) \\
& =\delta-\delta\left(\delta-\delta y_{1}\left(r_{1}^{i+1}, r_{2}^{i+2}\right)\right) \\
& =\delta-\delta^{2}+\delta^{2} y_{1}\left(r_{1}^{i+1}, r_{2}^{i+2}\right),
\end{aligned}
$$

which implies

$$
y_{1}\left(r_{1}^{i}, r_{2}^{i+1}\right) \geq y_{1}\left(r_{1}^{i+1}, r_{2}^{i+2}\right) \Leftrightarrow y_{1}\left(r_{1}^{i}, r_{2}^{i+1}\right) \leq y_{1}^{1, \mathrm{I}} .
$$

The proof for $\omega \in \Omega, \omega \neq 1, \mathrm{I}$, is analogous.

The following lemma says that if the reference point pair is in $P_{\omega}$ now and at all future odd time points, then player 1 must propose $x^{\omega}$. A similar result holds for $Q_{\omega}$.

Lemma B.3 If $\left(r_{1}^{k}, r_{2}^{k}\right) \in P_{\omega}$ for all $k \geq i$, then $x_{2}\left(r_{1}^{i}, r_{2}^{i}\right)=x_{2}^{\omega}$. Similarly, if $\left(r_{1}^{k}, r_{2}^{k+1}\right) \in Q_{\omega}$ for all $k \geq i$, then $y_{1}\left(r_{1}^{i}, r_{2}^{i+1}\right)=y_{1}^{\omega}$.

Proof. Observe that if $\left(r_{1}^{k}, r_{2}^{k}\right) \in P_{\omega}$ for all $k \geq i$, then by Lemma B.1 it follows that $x_{2}\left(r_{1}^{i}, r_{2}^{i}\right)$ is either independent from the reference point pair $\left(r_{1}^{i}, r_{2}^{i}\right)$, or no offer is ever made that changes that reference point pair. Hence, $x_{2}\left(r_{1}^{i}, r_{2}^{i}\right)$ can be obtained as the sum of a geometric series. For instance, let $\left(r_{1}^{k}, r_{2}^{k}\right) \in P_{1, \mathrm{I}}$ for all $k \geq i$. Then by Lemma B.1,

$$
\begin{aligned}
x_{2}\left(r_{1}^{i}, r_{2}^{i}\right) & =\delta-\delta^{2}+\delta^{2} x_{2}\left(r_{1}^{i+1}, r_{2}^{i+1}\right) \\
& =\delta(1-\delta)+\delta^{2}\left(\delta-\delta^{2}+\delta^{2} x_{2}\left(r_{1}^{i+2}, r_{2}^{i+2}\right)\right) \\
& \left.=\delta(1-\delta)\left(1+\delta^{2}\right)+\delta^{4} x_{2}\left(r_{1}^{i+2}, r_{2}^{i+2}\right)\right) \\
& =\delta(1-\delta)\left(1+\delta^{2}+\delta^{4}+\ldots\right) \\
& =\delta(1-\delta) \times \frac{1}{1-\delta^{2}} \\
& =x_{2}^{1, \mathrm{I}} .
\end{aligned}
$$


The proof for $P_{\omega}$ where $\omega \neq 1, \mathrm{I}$ and for $Q_{\omega}$ where $\omega \in \Omega$ is analogous to the proof for $P_{1, \mathrm{I}}$.

The following lemma establishes some restrictions on how reference points can move through the sets $P$ and $Q$.

Lemma B.4 If $\left(r_{1}^{i}, r_{2}^{i}\right) \in P_{1, I I I}$, then $\left(r_{1}^{i}, r_{2}^{i+1}\right) \notin Q_{1, I}$.

If $\left(r_{1}^{i}, r_{2}^{i}\right) \in P_{2, I I I}$, then $\left(r_{1}^{i}, r_{2}^{i+1}\right) \notin Q_{2, I}$.

If $\left(r_{1}^{i}, r_{2}^{i+1}\right) \in Q_{3, I}$, then $\left(r_{1}^{i+1}, r_{2}^{i+1}\right) \notin P_{1, I}$.

If $\left(r_{1}^{i}, r_{2}^{i+1}\right) \in Q_{3, I I}$, then $\left(r_{1}^{i+1}, r_{2}^{i+1}\right) \notin P_{1, I I}$.

Proof. Let $\left(r_{1}^{i}, r_{2}^{i}\right) \in P_{1, \mathrm{III}}$ and assume $\left(r_{1}^{i}, r_{2}^{i+1}\right) \in Q_{1, \mathrm{I}}$. Then from the definitions of $P_{1, \text { III }}$ and $Q_{1, \mathrm{I}}$ we have

$$
\begin{aligned}
& y_{2}\left(r_{1}^{i}, r_{2}^{i+1}\right)>x_{2}\left(r_{1}^{i}, r_{2}^{i}\right) \geq r_{2}^{i}, \\
& r_{1}^{i}>x_{1}\left(r_{1}^{i+1}, r_{2}^{i+1}\right)>y_{1}\left(r_{1}^{i}, r_{2}^{i+1}\right), \text { and } \\
& r_{2}^{i+1}>y_{2}\left(r_{1}^{i+1}, r_{2}^{i+2}\right)>x_{2}\left(r_{1}^{i+1}, r_{2}^{i+1}\right) .
\end{aligned}
$$

Since $r_{1}^{i}>y_{1}\left(r_{1}^{i}, r_{2}^{i+1}\right)$ and $r_{2}^{i+1}>x_{2}\left(r_{1}^{i+1}, r_{2}^{i+1}\right)$ we have $r_{1}^{i+1}=r_{1}^{i}$ and $r_{2}^{i+2}=$ $r_{2}^{i+1}$ by (9). From (U1) it follows that

$$
y_{2}\left(r_{1}^{i}, r_{2}^{i+1}\right)=y_{2}\left(r_{1}^{i+1}, r_{2}^{i+2}\right) .
$$

Furthermore, since $x_{2}\left(r_{1}^{i}, r_{2}^{i}\right) \geq r_{2}^{i}$, (9) implies $r_{2}^{i+1}=x_{2}\left(r_{1}^{i}, r_{2}^{i}\right)$. Thus,

$$
r_{2}^{i+1}>y_{2}\left(r_{1}^{i+1}, r_{2}^{i+2}\right)=y_{2}\left(r_{1}^{i}, r_{2}^{i+1}\right)>x_{2}\left(r_{1}^{i}, r_{2}^{i}\right)=r_{2}^{i+1} .
$$

This is a contradiction.

The proofs of the other statements are analogous.

\section{B.2 Proof of Theorem 4.1}

In this section we prove a series of lemmas which are used in the proof of Theorem 4.1.

Lemma B.5 Let $\omega \in\{1, \mathrm{I}, 1, \mathrm{II}, 2, \mathrm{I}, 2, \mathrm{II}\}$. Then for all $\left(r_{1}^{i}, r_{2}^{i}\right) \in P_{\omega}$ we have $x\left(r_{1}^{i}, r_{2}^{i}\right)=x^{\omega}$. Similarly, for all $\left(r_{1}^{i}, r_{2}^{i+1}\right) \in Q_{\omega}$ we have $y\left(r_{1}^{i}, r_{2}^{i+1}\right)=y^{\omega}$.

Proof. Let $\left(r_{1}^{i}, r_{2}^{i}\right) \in P_{\omega}$ where $\omega \in\{1, \mathrm{I}, 1, \mathrm{II}, 2, \mathrm{I}, 2, \mathrm{II}\}$. Then $r_{1}^{i}>y_{1}\left(r_{1}^{i}, r_{2}^{i+1}\right)$ and $r_{2}^{i}>x_{2}\left(r_{1}^{i}, r_{2}^{i}\right)$. By (9) this implies $r_{1}^{i+1}=r_{1}^{i}$ and $r_{2}^{i+1}=r_{2}^{i}$. By (U1),

$$
x_{2}\left(r_{1}^{i}, r_{2}^{i}\right)=x_{2}\left(r_{1}^{i+1}, r_{2}^{i+1}\right) .
$$

By Lemma B. $2 x_{2}\left(r_{1}^{i}, r_{2}^{i}\right)=x_{2}^{\omega}$. The case for $Q_{\omega}$ is similar.

Lemma B.6 If $\left(r_{1}^{i}, r_{2}^{i+1}\right) \in Q_{3, I}$, then 

i. $y_{1}\left(r_{1}^{i}, r_{2}^{i+1}\right) \geq y_{1}^{3, I}$.
ii. $y_{1}\left(r_{1}^{i}, r_{2}^{i+1}\right) \leq y_{1}^{3, I}$.

Thus, $y_{1}\left(r_{1}^{i}, r_{2}^{i+1}\right)=y_{1}^{3, I}$.

Proof of Lemma B.6, part $i . \quad$ Let $\left(r_{1}^{i}, r_{2}^{i+1}\right) \in Q_{3, \mathrm{I}}$. From the definition of $Q_{3, \mathrm{I}}$ we have

$$
\begin{aligned}
& x_{1}\left(r_{1}^{i+1}, r_{2}^{i+1}\right)>y_{1}\left(r_{1}^{i}, r_{2}^{i+1}\right) \geq r_{1}^{i}, \text { and } \\
& r_{2}^{i+1}>y_{2}\left(r_{1}^{i+1}, r_{2}^{i+2}\right)>x_{2}\left(r_{1}^{i+1}, r_{2}^{i+1}\right) .
\end{aligned}
$$

Assume $y_{1}\left(r_{1}^{i}, r_{2}^{i+1}\right)<y_{1}^{3, \mathrm{I}}$. By Lemma B.2, $y_{1}\left(r_{1}^{i}, r_{2}^{i+1}\right)>y_{1}\left(r_{1}^{i+1}, r_{2}^{i+2}\right)$. Since $y_{1}\left(r_{1}^{i}, r_{2}^{i+1}\right) \geq r_{1}^{i}$ we have from (9) that $r_{1}^{i+1}=y_{1}\left(r_{1}^{i}, r_{2}^{i+1}\right)$. Hence, $r_{1}^{i+1}>$ $y_{1}\left(r_{1}^{i+1}, r_{2}^{i+2}\right)$. We have two possibilities:
a. $r_{1}^{i+1}>x_{1}\left(r_{1}^{i+2}, r_{2}^{i+2}\right)>y_{1}\left(r_{1}^{i+1}, r_{2}^{i+2}\right)$, i.e. $\left(r_{1}^{i+1}, r_{2}^{i+1}\right) \in P_{1, \mathrm{I}}$.
b. $x_{1}\left(r_{1}^{i+2}, r_{2}^{i+2}\right) \geq r_{1}^{i+1}>y_{1}\left(r_{1}^{i+1}, r_{2}^{i+2}\right)$, i.e. $\left(r_{1}^{i+1}, r_{2}^{i+1}\right) \in P_{2, \mathrm{I}}$.

By Lemma B.4, case a. can be ruled out. Hence, $\left(r_{1}^{i+1}, r_{2}^{i+1}\right) \in P_{2, \mathrm{I}}$. By Lemma B.5, $x_{2}\left(r_{1}^{i+1}, r_{2}^{i+1}\right)=x_{2}^{2, \mathrm{I}}$. Since $\left(r_{1}^{i}, r_{2}^{i+1}\right) \in Q_{3, \mathrm{I}}$, Lemma B.1 implies

$$
\begin{aligned}
y_{1}\left(r_{1}^{i}, r_{2}^{i+1}\right) & =\frac{\delta}{\mu_{1}}-\frac{\delta}{\mu_{1}} x_{2}\left(r_{1}^{i+1}, r_{2}^{i+1}\right) \\
& =\frac{\delta}{\mu_{1}}-\frac{\delta}{\mu_{1}} x_{2}^{2, \mathrm{I}} \\
& =\frac{\delta}{\mu_{1}} x_{1}^{2, \mathrm{I}} .
\end{aligned}
$$

By (9), we have $r_{1}^{i+1}=y_{1}\left(r_{1}^{i}, r_{2}^{i+1}\right)$. Note that $x_{1}^{2, \mathrm{I}}$ is a function of $r_{1}^{i+1}$, and therefore of $y_{1}\left(r_{1}^{i}, r_{2}^{i+1}\right)$. That is,

$$
\begin{aligned}
y_{1}\left(r_{1}^{i}, r_{2}^{i+1}\right) & =\frac{\delta}{\mu_{1}} \times \frac{\left(\mu_{1}-\delta\right)+\delta^{2} \lambda_{1} r_{1}^{i+1}}{\left(1+\lambda_{1}\right)-\delta^{2}} \\
& =\frac{\delta}{\mu_{1}} \times \frac{\left(\mu_{1}-\delta\right)+\delta^{2} \lambda_{1} y_{1}\left(r_{1}^{i}, r_{2}^{i+1}\right)}{\left(1+\lambda_{1}\right)-\delta^{2}} .
\end{aligned}
$$


Solving for $y_{1}\left(r_{1}^{i}, r_{2}^{i+1}\right)$ yields

$$
\begin{aligned}
y_{1}\left(r_{1}^{i}, r_{2}^{i+1}\right) & =\frac{\delta}{\mu_{1}} \times \frac{\mu_{1}-\delta}{1+\lambda_{1}-\delta^{2}-\delta^{2} \lambda_{1} \frac{\delta}{\mu_{1}}} \\
& =\frac{\delta\left(\mu_{1}-\delta\right)}{\left(1+\lambda_{1}\right) \mu_{1}-\delta^{2} \mu_{1}-\delta^{3} \lambda_{1}} \\
& =\frac{\delta\left(\mu_{1}-\delta\right)}{\left(1+\lambda_{1}\right) \mu_{1}-\delta^{2}-\delta^{2} \lambda_{1}+\delta^{3} \lambda_{1}-\delta^{3} \lambda_{1}} \\
& =\frac{\delta\left(\mu_{1}-\delta\right)}{\left(1+\lambda_{1}\right)\left(\mu_{1}-\delta^{2}\right)} \\
& =\frac{\delta}{1+\lambda_{1}+\delta} \\
& =y_{1}^{3, I},
\end{aligned}
$$

where we used the fact that

$$
\begin{aligned}
\left(1+\lambda_{1}\right)\left(\mu_{1}-\delta^{2}\right) & =\left(1+\lambda_{1}\right)\left(1+\lambda_{1}(1-\delta)-\delta^{2}\right) \\
& =\left(1+\lambda_{1}\right)\left((1+\delta)(1-\delta)+\lambda_{1}(1-\delta)\right) \\
& =\left(1+\lambda_{1}\right)(1-\delta)\left(1+\lambda_{1}+\delta\right) \\
& =\left(1-\delta+\lambda_{1}(1-\delta)\right)\left(1+\lambda_{1}+\delta\right) \\
& =\left(\mu_{1}-\delta\right)\left(1+\lambda_{1}+\delta\right) .
\end{aligned}
$$

Observe that $y_{1}\left(r_{1}^{i}, r_{2}^{i+1}\right)=y_{1}^{3, \mathrm{I}}$ is contradicting $y_{1}\left(r_{1}^{i}, r_{2}^{i+1}\right)<y_{1}^{3, \mathrm{I}}$, our initial assumption.

Before we can prove Part $i i$. we must make a similar argument for $Q_{3, \mathrm{II}}$.

Lemma B.7 If $\left(r_{1}^{i}, r_{2}^{i+1}\right) \in Q_{3, I I}$, then
i. $y_{1}\left(r_{1}^{i}, r_{2}^{i+1}\right) \geq y_{1}^{3, I I}$.
ii. $y_{1}\left(r_{1}^{i}, r_{2}^{i+1}\right) \leq y_{1}^{3, I I}$.

Thus, $y_{1}\left(r_{1}^{i}, r_{2}^{i+1}\right)=y_{1}^{3, I I}$.

Proof of Lemma B.7, Part $i$. Let $\left(r_{1}^{i}, r_{2}^{i+1}\right) \in Q_{3, \text { II }}$. From the definition of $Q_{3, \text { II }}$ it follows that

$$
\begin{aligned}
& x_{1}\left(r_{1}^{i+1}, r_{2}^{i+1}\right)>y_{1}\left(r_{1}^{i}, r_{2}^{i+1}\right) \geq r_{1}^{i}, \text { and } \\
& y_{2}\left(r_{1}^{i+1}, r_{2}^{i+1}\right) \geq r_{2}^{i+1}>x_{2}\left(r_{1}^{i+1}, r_{2}^{i+1}\right) .
\end{aligned}
$$

Assume $y_{1}\left(r_{1}^{i}, r_{2}^{i+1}\right)<y_{1}^{3, \text { II }}$. Thus, $y_{1}\left(r_{1}^{i}, r_{2}^{i+1}\right)>y_{1}\left(r_{1}^{i+1}, r_{2}^{i+2}\right)$ by Lemma B.2. Since $y_{1}\left(r_{1}^{i}, r_{2}^{i+1}\right) \geq r_{1}^{i}$, we have $r_{1}^{i+1}=y_{1}\left(r_{1}^{i}, r_{2}^{i+1}\right)$ by $(9)$. Hence, $r_{1}^{i+1}>$ $y_{1}\left(r_{1}^{i+1}, r_{2}^{i+2}\right)$, leaving two possibilities:

a. $r_{1}^{i+1} \geq x_{1}\left(r_{1}^{i+2}, r_{2}^{i+2}\right)>y_{1}\left(r_{1}^{i+1}, r_{2}^{i+2}\right)$, i.e. $\left(r_{1}^{i+1}, r_{2}^{i+1}\right) \in P_{1, \text { II }}$. 
b. $x_{1}\left(r_{1}^{i+2}, r_{2}^{i+2}\right)>r_{1}^{i+1}>y_{1}\left(r_{1}^{i+1}, r_{2}^{i+2}\right)$, i.e. $\left(r_{1}^{i+1}, r_{2}^{i+1}\right) \in P_{2, \mathrm{II}}$.

Case a. is ruled out by Lemma B.4. Hence, $\left(r_{1}^{i+1}, r_{2}^{i+1}\right) \in P_{2, \mathrm{II}}$, and thus by Lemma B.5, $x_{2}\left(r_{1}^{i+1}, r_{2}^{i+1}\right)=x_{2}^{2, \text { II }}$. Since $\left(r_{1}^{i}, r_{2}^{i+1}\right) \in Q_{3, \text { II }}$, we have from Lemma B.1 that

$$
\begin{aligned}
y_{1}\left(r_{1}^{i}, r_{2}^{i+1}\right) & =\frac{\delta}{\mu_{1}}-\frac{\delta}{\mu_{1}} x_{2}\left(r_{1}^{i+1}, r_{2}^{i+1}\right) \\
& =\frac{\delta}{\mu_{1}}-\frac{\delta}{\mu_{1}} x_{2}^{2, \mathrm{II}} \\
& =\frac{\delta}{\mu_{1}} x_{1}^{2, \mathrm{II}} .
\end{aligned}
$$

Note that $y_{1}\left(r_{1}^{i}, r_{2}^{i+1}\right)=r_{1}^{i+1}$ and that $x_{1}^{2, \mathrm{II}}$ is a function of $r_{1}^{i+1}$. That is,

$$
\begin{aligned}
y_{1}\left(r_{1}^{i}, r_{2}^{i+1}\right) & =\frac{\left(1+\lambda_{1}\right)\left(\left(\mu_{2}-\delta\right)+\delta \lambda_{2}\left(1-r_{2}^{i+1}\right)\right)+\delta^{2} \lambda_{1} r_{1}^{i+1}}{\left(1+\lambda_{1}\right)\left(1+\lambda_{2}\right)-\delta^{2}} \\
& =\frac{\left(1+\lambda_{1}\right)\left(\left(\mu_{2}-\delta\right)+\delta \lambda_{2}\left(1-r_{2}^{i+1}\right)\right)+\delta^{2} \lambda_{1} y_{1}\left(r_{1}^{i}, r_{2}^{i+1}\right)}{\left(1+\lambda_{1}\right)\left(1+\lambda_{2}\right)-\delta^{2}} .
\end{aligned}
$$

Solving for $y_{1}\left(r_{1}^{i}, r_{2}^{i+1}\right)$ yields

$$
\begin{aligned}
y_{1}\left(r_{1}^{i}, r_{2}^{i+1}\right) & =\frac{\delta}{\mu_{1}} \times \frac{\left(1+\lambda_{1}\right)\left(\mu_{2}-\delta+\delta \lambda_{2}\left(1-r_{2}^{i+1}\right)\right)}{\left(1+\lambda_{1}\right)\left(1+\lambda_{2}\right)-\delta^{2}-\delta^{2} \lambda_{1} \frac{\delta}{\mu_{1}}} \\
& =\frac{\delta\left(1+\lambda_{1}\right)\left(\mu_{2}-\delta+\delta \lambda_{2}\left(1-r_{2}^{i+1}\right)\right)}{\left(1+\lambda_{1}\right)\left(1+\lambda_{2}\right) \mu_{1}-\delta^{2} \mu_{1}-\delta^{3} \lambda_{1}} \\
& =\frac{\delta\left(1+\lambda_{1}\right)\left(\mu_{2}-\delta+\delta \lambda_{2}\left(1-r_{2}^{i+1}\right)\right)}{\left(1+\lambda_{1}\right)\left(1+\lambda_{2}\right) \mu_{1}-\delta^{2}-\delta^{2} \lambda_{1}+\delta^{3} \lambda_{1}-\delta^{3} \lambda_{1}} \\
& =\frac{\delta\left(1+\lambda_{1}\right)\left(\mu_{2}-\delta+\delta \lambda_{2}\left(1-r_{2}^{i+1}\right)\right)}{\left(1+\lambda_{1}\right)\left(\left(1+\lambda_{2}\right) \mu_{1}-\delta^{2}\right)} \\
& =\frac{\delta\left(\mu_{2}-\delta+\delta \lambda_{2}\left(1-r_{2}^{i+1}\right)\right)}{\left(1+\lambda_{2}\right) \mu_{1}-\delta^{2}} \\
& =y_{1}^{3, \mathrm{II}} .
\end{aligned}
$$

This contradicts $y_{1}\left(r_{1}^{i}, r_{2}^{i+1}\right)<y_{1}^{3, \text { II }}$.

This result allows us to prove the second part of Lemma B.6.

Proof of Lemma B.6, Part ii. Let $\left(r_{1}^{i}, r_{2}^{i+1}\right) \in Q_{3, \mathrm{I}}$. By the definition of $Q_{3, \mathrm{I}}$ we have

$$
\begin{aligned}
& x_{1}\left(r_{1}^{i+1}, r_{2}^{i+1}\right)>y_{1}\left(r_{1}^{i}, r_{2}^{i+1}\right) \geq r_{1}^{i}, \text { and } \\
& r_{2}^{i+1}>y_{2}\left(r_{1}^{i+1}, r_{2}^{i+2}\right)>x_{2}\left(r_{1}^{i+1}, r_{2}^{i+1}\right) .
\end{aligned}
$$


Assume $y_{1}\left(r_{1}^{i}, r_{2}^{i+1}\right)>y_{1}^{3, \mathrm{I}}$. Then by Lemma B.2 we have $y_{1}\left(r_{1}^{i+1}, r_{2}^{i+2}\right)>$ $y_{1}\left(r_{1}^{i}, r_{2}^{i+1}\right)$. Observe that $y_{1}\left(r_{1}^{i}, r_{2}^{i+1}\right) \geq r_{1}^{i}$, and thus by $(9) y_{1}\left(r_{1}^{i}, r_{2}^{i+1}\right)=r_{1}^{i+1}$. Hence, $y_{1}\left(r_{1}^{i+1}, r_{2}^{i+2}\right)>r_{1}^{i+1}$, implying $\left(r_{1}^{i+1}, r_{2}^{i+1}\right) \in P_{3, \mathrm{I}}$. Then from Lemma B.1, $y_{1}\left(r_{1}^{i}, r_{2}^{i+1}\right)>y_{1}^{3, \mathrm{I}}$ and $y_{1}\left(r_{1}^{i+1}, r_{2}^{i+2}\right)>y_{1}\left(r_{1}^{i}, r_{2}^{i+1}\right)$, we have

$$
x_{2}\left(r_{1}^{i+1}, r_{2}^{i+1}\right)=\delta-\delta y_{1}\left(r_{1}^{i+1}, r_{2}^{i+2}\right)<\delta-\delta y_{1}\left(r_{1}^{i}, r_{2}^{i+1}\right)<\delta-\delta y_{1}^{3, \mathrm{I}}=x_{2}^{3, \mathrm{I}} .
$$

By Lemma B.2 this implies $x_{2}\left(r_{1}^{i+1}, r_{2}^{i+1}\right)>x_{2}\left(r_{1}^{i+2}, r_{2}^{i+2}\right)$. Observe that, by (9), $r_{2}^{i+1}>x_{2}\left(r_{1}^{i+1}, r_{2}^{i+1}\right)$ implies $r_{2}^{i+2}=r_{2}^{i+1}$, and thus

$$
r_{2}^{i+2}=r_{2}^{i+1}>x_{2}\left(r_{1}^{i+1}, r_{2}^{i+1}\right)>x_{2}\left(r_{1}^{i+2}, r_{2}^{i+2}\right)
$$

This leaves two possibilities.

a. $r_{2}^{i+2}>y_{2}\left(r_{1}^{i+2}, r_{2}^{i+3}\right)>x_{2}\left(r_{1}^{i+2}, r_{2}^{i+2}\right)$, i.e. $\left(r_{1}^{i+1}, r_{2}^{i+2}\right) \in Q_{3, \mathrm{I}}$.

b. $y_{2}\left(r_{1}^{i+2}, r_{2}^{i+3}\right) \geq r_{2}^{i+2}>x_{2}\left(r_{1}^{i+2}, r_{2}^{i+2}\right)$, i.e. $\left(r_{1}^{i+1}, r_{2}^{i+2}\right) \in Q_{3, \mathrm{II}}$.

Take case b., i.e. $\left(r_{1}^{i+1}, r_{2}^{i+2}\right) \in Q_{3, \mathrm{II}}$. Then

$$
y_{2}\left(r_{1}^{i+2}, r_{2}^{i+3}\right) \geq r_{2}^{i+2}=r_{2}^{i+1}>y_{2}\left(r_{1}^{i+1}, r_{2}^{i+2}\right),
$$

which implies $y_{1}\left(r_{1}^{i+1}, r_{2}^{i+2}\right)>y_{1}\left(r_{1}^{i+2}, r_{2}^{i+3}\right)$. By Lemma B.2 we have $y_{1}\left(r_{1}^{i+1}\right.$, $\left.r_{2}^{i+2}\right)<y_{1}^{3, \text { II }}$. This contradicts part $i$. of Lemma B.7.

Hence, case a. must hold, i.e. $\left(r_{1}^{i+1}, r_{2}^{i+2}\right) \in Q_{3, \text { I. }}$. Note that $x_{2}\left(r_{1}^{i+2}, r_{2}^{i+2}\right)<$ $x_{2}\left(r_{1}^{i+1}, r_{2}^{i+1}\right)<x_{2}^{3, \mathrm{I}}$. Then

$$
y_{1}\left(r_{1}^{i+1}, r_{2}^{i+2}\right)=\frac{\delta}{\mu_{1}}-\frac{\delta}{\mu_{1}} x_{2}\left(r_{1}^{i+2}, r_{2}^{i+2}\right)>\frac{\delta}{\mu_{1}}-\frac{\delta}{\mu_{1}} x_{2}^{3, \mathrm{I}}=y_{1}^{3, \mathrm{I}} .
$$

Thus, if $\left(r_{1}^{i}, r_{2}^{i+1}\right) \in Q_{3, \mathrm{I}}$ and $y_{1}\left(r_{1}^{i}, r_{2}^{i+1}\right)>y_{1}^{3, \mathrm{I}}$, then $\left(r_{1}^{i+1}, r_{2}^{i+2}\right) \in Q_{3, \mathrm{I}}$ and $y_{1}\left(r_{1}^{i+1}, r_{2}^{i+2}\right)>y_{1}^{3, \mathrm{I}}$. Thus, for all $k \geq i$ we have $\left(r_{1}^{k}, r_{2}^{k+1}\right) \in Q_{3, \mathrm{I}}$. Then by Lemma B.3 we have that $y_{1}\left(r_{1}^{i}, r_{2}^{i+1}\right)=y_{1}^{3, \mathrm{I}}$. This contradicts $y_{1}\left(r_{1}^{i}, r_{2}^{i+1}\right)>y_{1}^{3, \mathrm{I}}$.

We can now also complete the proof of Lemma B.7.

Proof of Lemma B.7, Part ii. Let $\left(r_{1}^{i}, r_{2}^{i+1}\right) \in Q_{3, \mathrm{II}}$. By definition of $Q_{3, \mathrm{II}}$ we have

$$
\begin{aligned}
& x_{1}\left(r_{1}^{i+1}, r_{2}^{i+1}\right)>y_{1}\left(r_{1}^{i}, r_{2}^{i+1}\right) \geq r_{1}^{i} \\
& y_{2}\left(r_{1}^{i+1}, r_{2}^{i+2}\right) \geq r_{2}^{i+1}>x_{2}\left(r_{1}^{i+1}, r_{2}^{i+1}\right) .
\end{aligned}
$$

Assume $y_{1}\left(r_{1}^{i}, r_{2}^{i+1}\right)>y_{1}^{3, \text { II }}$. Then by Lemma B.2 we have $y_{1}\left(r_{1}^{i}, r_{2}^{i+1}\right)<$ $y_{1}\left(r_{1}^{i+1}, r_{2}^{i+2}\right)$. Since $y_{1}\left(r_{1}^{i}, r_{2}^{i+1}\right) \geq r_{1}^{i}$, (9) says that $r_{1}^{i+1}=y_{1}\left(r_{1}^{i}, r_{2}^{i+1}\right)$. Hence, $y_{1}\left(r_{1}^{i+1}, r_{2}^{i+2}\right)>r_{1}^{i+1}$, which implies $\left(r_{1}^{i+1}, r_{2}^{i+1}\right) \in P_{3, \mathrm{II}}$. From Lemma B.1, 
$y_{1}\left(r_{1}^{i}, r_{2}^{i+1}\right)<y_{1}\left(r_{1}^{i+1}, r_{2}^{i+2}\right), y_{1}^{3, \text { II }}<y_{1}\left(r_{1}^{i}, r_{2}^{i+1}\right)$, and the fact that $r_{2}^{i+2}=$ $\max \left\{r_{2}^{i+1}, x_{2}\left(r_{1}^{i+1}, r_{2}^{i+1}\right)\right\}=r_{2}^{i+1}$, we have

$$
\begin{aligned}
x_{2}\left(r_{1}^{i+1}, r_{2}^{i+1}\right) & =\frac{\delta\left(1+\lambda_{2} r_{2}^{i+2}\right)}{1+\lambda_{2}}-\frac{\delta}{1+\lambda_{2}} y_{1}\left(r_{1}^{i+1}, r_{2}^{i+2}\right) \\
& <\frac{\delta\left(1+\lambda_{2} r_{2}^{i+2}\right)}{1+\lambda_{2}}-\frac{\delta}{1+\lambda_{2}} y_{1}\left(r_{1}^{i}, r_{2}^{i+1}\right) \\
& <\frac{\delta\left(1+\lambda_{2} r_{2}^{i+2}\right)}{1+\lambda_{2}}-\frac{\delta}{1+\lambda_{2}} y_{1}^{3, \mathrm{II}} \\
& =\frac{\delta\left(1+\lambda_{2} r_{2}^{i+1}\right)}{1+\lambda_{2}}-\frac{\delta}{1+\lambda_{2}} y_{1}^{3, \mathrm{II}} \\
& =x_{2}^{3, \mathrm{II}} .
\end{aligned}
$$

By Lemma B.2 this implies $x_{2}\left(r_{1}^{i+1}, r_{2}^{i+1}\right)>x_{2}\left(r_{1}^{i+2}, r_{2}^{i+2}\right)$. Since $r_{2}^{i+2}=r_{2}^{i+1}>$ $x_{2}\left(r_{1}^{i+1}, r_{2}^{i+1}\right)$, this implies $r_{2}^{i+2}>x_{2}\left(r_{1}^{i+2}, r_{2}^{i+2}\right)$. Then there are two possibilities:

a. $r_{2}^{i+2}>y_{2}\left(r_{1}^{i+2}, r_{2}^{i+3}\right)>x_{2}\left(r_{1}^{i+2}, r_{2}^{i+2}\right)$, i.e. $\left(r_{1}^{i+1}, r_{2}^{i+2}\right) \in Q_{3, \mathrm{I}}$.

b. $y_{2}\left(r_{1}^{i+2}, r_{2}^{i+3}\right) \geq r_{2}^{i+2}>x_{2}\left(r_{1}^{i+2}, r_{2}^{i+2}\right)$, i.e. $\left(r_{1}^{i+1}, r_{2}^{i+2}\right) \in Q_{3, \mathrm{II}}$.

Take case a., i.e. $\left(r_{1}^{i+1}, r_{2}^{i+2}\right) \in Q_{3, \mathrm{I}}$. Observe that

$$
y_{2}\left(r_{1}^{i+1}, r_{2}^{i+2}\right) \geq r_{2}^{i+1}=r_{2}^{i+2}>y_{2}\left(r_{1}^{i+2}, r_{2}^{i+3}\right),
$$

and thus $y_{1}\left(r_{1}^{i+1}, r_{2}^{i+2}\right)<y_{1}\left(r_{1}^{i+2}, r_{2}^{i+3}\right)$. Lemma B.2 now implies $y_{1}\left(r_{1}^{i+1}, r_{2}^{i+2}\right)>$ $y_{1}^{3, \mathrm{I}}$. This contradicts part $i$. of Lemma B.6.

Hence, case b. must hold, i.e. $\left(r_{1}^{i+1}, r_{2}^{i+2}\right) \in Q_{3, \mathrm{II}}$. Since $x_{2}\left(r_{1}^{i+1}, r_{2}^{i+1}\right)>$ $x_{2}^{3, \text { II }}$ and $x_{2}\left(r_{1}^{i+2}, r_{2}^{i+2}\right)>x_{2}\left(r_{1}^{i+1}, r_{2}^{i+1}\right)$, we have from Lemma B.1

$$
y_{1}\left(r_{1}^{i+1}, r_{2}^{i+2}\right)=\frac{\delta}{\mu_{1}}-\frac{\delta}{\mu_{1}} x_{2}\left(r_{1}^{i+2}, r_{2}^{i+2}\right)>\frac{\delta}{\mu_{1}}-\frac{\delta}{\mu_{1}} x_{2}^{3, \mathrm{II}}=y_{1}^{3, \mathrm{II}} \text {. }
$$

Thus, $\left(r_{1}^{i}, r_{2}^{i+1}\right) \in Q_{3, \mathrm{II}}$ and $y_{1}\left(r_{1}^{i}, r_{2}^{i+1}\right)>y_{1}^{3, \text { II }}$ implies $\left(r_{1}^{i+1}, r_{2}^{i+2}\right) \in Q_{3, \mathrm{II}}$ and $y_{1}\left(r_{1}^{i+1}, r_{2}^{i+2}\right)>y_{1}^{3, \mathrm{II}}$. Then, for all $k \geq i$ we have $\left(r_{1}^{k}, r_{2}^{k+1}\right) \in Q_{3, \mathrm{II}}$, which by Lemma B.3 implies $y_{1}\left(r_{1}^{i}, r_{2}^{i+1}\right)=y_{1}^{3, \mathrm{II}}$. This contradicts $y_{1}\left(r_{1}^{i}, r_{2}^{i+1}\right)>y_{1}^{3, \mathrm{II}}$.

Similar results hold in $P_{2, \mathrm{III}}$ and $P_{1, \mathrm{III}}$.

Lemma B.8 If $\left(r_{1}^{i}, r_{2}^{i}\right) \in P_{1, I I I}$, then $x_{2}\left(r_{1}^{i}, r_{2}^{i}\right)=x_{2}^{1, I I I}$.

Lemma B.9 If $\left(r_{1}^{i}, r_{2}^{i}\right) \in P_{2, I I I}$, then $x_{2}\left(r_{1}^{i}, r_{2}^{i}\right)=x_{2}^{2, I I I}$.

The proofs of these lemmas are analogous to the proofs of Lemmas B.6 and B.7 respectively.

Lemma B.10 If $\left(r_{1}^{i}, r_{2}^{i}\right) \in P_{3, I I I}$, then 

i. $x_{2}\left(r_{1}^{i}, r_{2}^{i}\right) \geq x_{2}^{3, I I I}$.
ii. $x_{2}\left(r_{1}^{i}, r_{2}^{i}\right) \leq x_{2}^{3, I I I}$.

Thus, $x_{2}\left(r_{1}^{i}, r_{2}^{i}\right)=x_{2}^{3, I I I}$.

Proof of Lemma B.10, Part $i$. Let $\left(r_{1}^{i}, r_{2}^{i}\right) \in P_{3, \mathrm{III}}$. By the definition of $P_{3, \text { III }}$ we have

$$
\begin{aligned}
& y_{2}\left(r_{1}^{i}, r_{2}^{i+1}\right)>x_{2}\left(r_{1}^{i}, r_{2}^{i}\right) \geq r_{2}^{i}, \\
& x_{1}\left(r_{1}^{i+1}, r_{2}^{i+1}\right)>y_{1}\left(r_{1}^{i}, r_{2}^{i+1}\right) \geq r_{1}^{i} .
\end{aligned}
$$

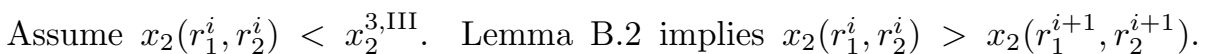
Since $x_{2}\left(r_{1}^{i}, r_{2}^{i}\right) \geq r_{2}^{i}$, we have from (9) that $r_{2}^{i+1}=x_{2}\left(r_{1}^{i}, r_{2}^{i}\right)$. Hence, $r_{2}^{i+1}>$ $x_{2}\left(r_{1}^{i+1}, r_{2}^{i+1}\right)$. Then there are two possibilities:

a. $r_{2}^{i+1}>y_{2}\left(r_{1}^{i+1}, r_{2}^{i+2}\right)>x_{2}\left(r_{1}^{i+1}, r_{2}^{i+1}\right)$, i.e. $\left(r_{1}^{i}, r_{2}^{i+1}\right) \in Q_{3, \mathrm{I}}$.

b. $y_{2}\left(r_{1}^{i+1}, r_{2}^{i+2}\right) \geq r_{2}^{i+1}>x_{2}\left(r_{1}^{i+1}, r_{2}^{i+1}\right)$, i.e. $\left(r_{1}^{i}, r_{2}^{i+1}\right) \in Q_{3, \mathrm{II}}$.

Take case a., i.e. $\left(r_{1}^{i}, r_{2}^{i+1}\right) \in Q_{3, \mathrm{I}}$. From Lemma B.6 we have $y_{1}\left(r_{1}^{i}, r_{2}^{i+1}\right)=y_{1}^{3, \mathrm{I}}$. From Lemma B.1 it follows that $x_{2}\left(r_{1}^{i}, r_{2}^{i}\right)=\frac{\delta}{\mu_{2}}-\frac{\delta}{\mu_{2}} y_{1}^{3, \mathrm{I}}=\frac{\delta}{\mu_{2}} y_{2}^{3, \mathrm{I}}$. Observe that $\mu_{2}\left(\mu_{1}-\delta^{2}\right)<\mu_{1} \mu_{2}-\delta^{2}$. Thus,

$$
\begin{gathered}
y_{2}^{3, \mathrm{I}}=\frac{1+\lambda_{1}}{1+\lambda_{1}+\delta}=\frac{\left(1+\lambda_{1}\right)(1-\delta)}{\left(1+\lambda_{1}+\delta\right)(1-\delta)}=\frac{\left(1-\delta+\lambda_{1}(1-\delta)\right)}{1-\delta+\lambda_{1}(1-\delta)+\delta-\delta^{2}} \\
=\frac{\mu_{2}}{\mu_{2}} \times \frac{\left(\mu_{1}-\delta\right)}{\mu_{1}-\delta^{2}}>\frac{\mu_{2}\left(\mu_{1}-\delta\right)}{\mu_{1} \mu_{2}-\delta^{2}}=y_{2}^{3, \text { III }} .
\end{gathered}
$$

Then $x_{2}\left(r_{1}^{i}, r_{2}^{i}\right)>\frac{\delta}{\mu_{2}} y_{2}^{3, \mathrm{III}}=x_{2}^{3, \mathrm{III}}$, contradicting the initial assumption $x_{2}\left(r_{1}^{i}\right.$, $\left.r_{2}^{i}\right)<x_{2}^{3, \mathrm{III}}$.

Take case b., i.e., $\left(r_{1}^{i}, r_{2}^{i+1}\right) \in Q_{3, \mathrm{II}}$. By Lemma B.1, $x_{2}\left(r_{1}^{i}, r_{2}^{i}\right)=\frac{\delta}{\mu_{2}} y_{2}^{3, \text { II }}$. Note that $r_{2}^{i+1}=x_{2}\left(r_{1}^{i}, r_{2}^{i}\right)$ by (9), and that $y_{2}^{3, \text { II }}$ is a function of $r_{2}^{i+1}$. That is,

$$
\begin{aligned}
x_{2}\left(r_{1}^{i}, r_{2}^{i}\right) & =\frac{\delta}{\mu_{2}} \times \frac{\left(\mu_{1}-\delta\right)\left(1+\lambda_{2}\right)+\delta^{2} \lambda_{2} r_{2}^{i+1}}{\mu_{1}\left(1+\lambda_{2}\right)-\delta^{2}} \\
& =\frac{\delta}{\mu_{2}} \times \frac{\left(\mu_{1}-\delta\right)\left(1+\lambda_{2}\right)+\delta^{2} \lambda_{2} x_{2}\left(r_{1}^{i}, r_{2}^{i}\right)}{\mu_{1}\left(1+\lambda_{2}\right)-\delta^{2}} .
\end{aligned}
$$

Solving for $x_{2}\left(r_{1}^{i}, r_{2}^{i}\right)$ yields

$$
\begin{gathered}
x_{2}\left(r_{1}^{i}, r_{2}^{i}\right)=\frac{\delta}{\mu_{2}} \times \frac{\left(\mu_{1}-\delta\right)\left(1+\lambda_{2}\right)}{\mu_{1}\left(1+\lambda_{2}\right)-\delta^{2}-\delta^{2} \lambda_{2} \frac{\delta}{\mu_{2}}}=\frac{\delta\left(\mu_{1}-\delta\right)\left(1+\lambda_{2}\right)}{\mu_{1} \mu_{2}\left(1+\lambda_{2}\right)-\delta^{2} \mu_{2}-\delta^{3} \lambda_{2}} \\
=\frac{\delta\left(\mu_{1}-\delta\right)\left(1+\lambda_{2}\right)}{\mu_{1} \mu_{2}\left(1+\lambda_{2}\right)-\delta^{2}-\delta^{2} \lambda_{2}+\delta^{3} \lambda_{2}-\delta^{3} \lambda_{2}}=\frac{\delta\left(\mu_{1}-\delta\right)}{\mu_{1} \mu_{2}-\delta^{2}}=x_{2}^{3, \text { III }} .
\end{gathered}
$$


This contradicts $x_{2}\left(r_{1}^{i}, r_{2}^{i}\right)<x_{2}^{3, \text { III }}$.

Before we can complete the proof of Lemma B.10, we need a similar result for $Q_{3, \mathrm{III}}$.

Lemma B.11 If $\left(r_{1}^{i}, r_{2}^{i+1}\right) \in Q_{3, I I I}$, then
i. $y_{1}\left(r_{1}^{i}, r_{2}^{i+1}\right) \geq y_{1}^{3, I I I}$,
ii. $y_{1}\left(r_{1}^{i}, r_{2}^{i+1}\right) \leq y_{1}^{3, I I I}$.

Thus, $y_{1}\left(r_{1}^{i}, r_{2}^{i+1}\right)=y_{1}^{3, I I I}$.

Proof of Lemma B.11, Part $i$. This is analogous to the proof of Lemma B.10 Part $i$.

We continue with the second part of Lemma B.10.

Proof of Lemma B.10, Part ii. Let $\left(r_{1}^{i}, r_{2}^{i}\right) \in P_{3, \text { III }}$. By definition of $P_{3, \text { III }}$ we have

$$
\begin{aligned}
& y_{2}\left(r_{1}^{i}, r_{2}^{i+1}\right)>x_{2}\left(r_{1}^{i}, r_{2}^{i}\right) \geq r_{2}^{i} \text {, and } \\
& x_{1}\left(r_{1}^{i+1}, r_{2}^{i+1}\right)>y_{1}\left(r_{1}^{i}, r_{2}^{i+1}\right) \geq r_{1}^{i} .
\end{aligned}
$$

Assume $x_{2}\left(r_{1}^{i}, r_{2}^{i}\right)>x_{2}^{3, \text { III }}$. Then by Lemma B.2 $x_{2}\left(r_{1}^{i}, r_{2}^{i}\right)<x_{2}\left(r_{1}^{i+1}, r_{2}^{i+1}\right)$. Since $x_{2}\left(r_{1}^{i}, r_{2}^{i}\right) \geq r_{2}^{i}$, we have $r_{2}^{i+1}=x_{2}\left(r_{1}^{i}, r_{2}^{i}\right)$ by (9). Thus, $r_{2}^{i+1}<x_{2}\left(r_{1}^{i+1}\right.$, $\left.r_{2}^{i+1}\right)$, implying $\left(r_{1}^{i}, r_{2}^{i+1}\right) \in Q_{3, \mathrm{III}}$. By the first part of Lemma B.11 this implies that $y_{1}\left(r_{1}^{i}, r_{2}^{i+1}\right) \geq y_{1}^{3, \text { III }}$. Then from Lemma B.1 and the construction of $x^{3, \text { III }}$ we obtain

$$
x_{2}\left(r_{1}^{i}, r_{2}^{i}\right)=\frac{\delta}{\mu_{2}}-\frac{\delta}{\mu_{2}} y_{1}\left(r_{1}^{i}, r_{2}^{i+1}\right) \leq \frac{\delta}{\mu_{2}}-\frac{\delta}{\mu_{2}} y_{1}^{3, \mathrm{III}}=x_{2}^{3, \mathrm{III}} .
$$

This contradicts $x_{2}\left(r_{1}^{i}, r_{2}^{i}\right)>x_{2}^{3, \text { III }}$.

In a similar way we can complete the proof of Lemma B.11.

Proof of Lemma B.11, Part ii. Analogous to the proof of Lemma B.10, Part ii.

redWe can now obtain the offers made in the sets $P_{3, \mathrm{I}}$ and $P_{3, \mathrm{II}}$.

Lemma B.12 If $\left(r_{1}^{i}, r_{2}^{i}\right) \in P_{3, I}$ then $x_{2}\left(r_{1}^{i}, r_{2}^{i}\right)=x_{2}^{3, I}$.

Proof. Let $\left(r_{1}^{i}, r_{2}^{i}\right) \in P_{3, \mathrm{I}}$. By definition of $P_{3, \mathrm{I}}$ we have

$$
\begin{aligned}
& r_{2}^{i}>y_{2}\left(r_{1}^{i}, r_{2}^{i+1}\right)>x_{2}\left(r_{1}^{i}, r_{2}^{i}\right), \text { and } \\
& x_{1}\left(r_{1}^{i+1}, r_{2}^{i+1}\right)>y_{1}\left(r_{1}^{i}, r_{2}^{i+1}\right) \geq r_{1}^{i} .
\end{aligned}
$$

Assume $x_{2}\left(r_{1}^{i}, r_{2}^{i}\right) \neq x_{2}^{3, \mathrm{I}}$. We have three mutually exclusive and exhaustive cases. 
- $\left(r_{1}^{i}, r_{2}^{i+1}\right) \in Q_{3, \mathrm{I}}$ : Note that $\left(r_{1}^{i}, r_{2}^{i}\right) \in P_{3, \mathrm{I}}$ by Lemma B.1 implies $x_{2}\left(r_{1}^{i}, r_{2}^{i}\right)$ $=\delta-\delta y_{1}\left(r_{1}^{i}, r_{2}^{i+1}\right)=\delta y_{2}\left(r_{1}^{i}, r_{2}^{i+1}\right)$. Then by Lemma B.6 and the construction of $x^{3, \mathrm{I}}$ this implies $x_{2}\left(r_{1}^{i}, r_{2}^{i}\right)=\delta y_{2}^{3, \mathrm{I}}=x_{2}^{3, \mathrm{I}}$, contradicting $x_{2}\left(r_{1}^{i}, r_{2}^{i}\right) \neq$ $x_{2}^{3, I}$.

- $\left(r_{1}^{i}, r_{2}^{i+1}\right) \in Q_{3, \mathrm{II}}$ : Since $\left(r_{1}^{i}, r_{2}^{i}\right) \in P_{3, \mathrm{I}}$ and $\left(r_{1}^{i}, r_{2}^{i+1}\right) \in Q_{3, \mathrm{II}}$ we have

$$
y_{2}\left(r_{1}^{i+1}, r_{2}^{i+2}\right) \geq r_{2}^{i+1}=\max \left\{r_{2}^{i}, x_{2}\left(r_{1}^{i}, r_{2}^{i}\right)\right\}=r_{2}^{i}>y_{2}\left(r_{1}^{i}, r_{2}^{i+1}\right) .
$$

However, $y_{2}\left(r_{1}^{i}, r_{2}^{i+1}\right)=y_{2}^{3, \text { II }}$ by Lemma B.7, and this implies $y_{2}\left(r_{1}^{i}, r_{2}^{i+1}\right)$ $=y_{2}\left(r_{1}^{i+1}, r_{2}^{i+2}\right)$ by Lemma B.2. This contradicts the above.

- $\left(r_{1}^{i}, r_{2}^{i+1}\right) \in Q_{3, \text { III }}$ : By Lemma B.1, Lemma B.11, inequality (11), and the construction of $x^{3, \mathrm{I}}$, we have

$$
x_{2}\left(r_{1}^{i}, r_{2}^{i}\right)=\delta-\delta y_{1}\left(r_{1}^{i}, r_{2}^{i+1}\right)=\delta y_{2}^{3, \mathrm{III}}<\delta y_{2}^{3, \mathrm{I}}=x_{2}^{3, \mathrm{I}} .
$$

By Lemma B.2 this implies $x_{2}\left(r_{1}^{i}, r_{2}^{i}\right)>x_{2}\left(r_{1}^{i+1}, r_{2}^{i+1}\right)$. Since $r_{2}^{i}>x_{2}\left(r_{1}^{i}, r_{2}^{i}\right)$ we have by (9) that $r_{2}^{i+1}=r_{2}^{i}$, implying $r_{2}^{i+1}>x_{2}\left(r_{1}^{i+1}, r_{2}^{i+1}\right)$. This implies $\left(r_{1}^{i}, r_{2}^{i+1}\right) \notin Q_{3, \mathrm{III}}$, a contradiction.

It follows that $x_{2}\left(r_{1}^{i}, r_{2}^{i}\right)=x_{2}^{3, \mathrm{I}}$.

Lemma B.13 If $\left(r_{1}^{i}, r_{2}^{i}\right) \in P_{3, I I}$ then $x_{2}\left(r_{1}^{i}, r_{2}^{i}\right)=x_{2}^{3, I I}$.

Proof. Let $\left(r_{1}^{i}, r_{2}^{i}\right) \in P_{3, \mathrm{II}}$. By definition of $P_{3, \mathrm{II}}$ we have

$$
\begin{aligned}
& y_{2}\left(r_{1}^{i}, r_{2}^{i+1}\right) \geq r_{2}^{i}>x_{2}\left(r_{1}^{i}, r_{2}^{i}\right) \\
& x_{1}\left(r_{1}^{i+1}, r_{2}^{i+1}\right)>y_{1}\left(r_{1}^{i}, r_{2}^{i+1}\right) \geq r_{1}^{i} .
\end{aligned}
$$

Assume $x_{2}\left(r_{1}^{i}, r_{2}^{i}\right) \neq x_{2}^{3, \text { II }}$. Then we distinguish three mutually exclusive and exhaustive cases.

- $\left(r_{1}^{i}, r_{2}^{i+1}\right) \in Q_{3, \mathrm{I}}$ : Since $r_{2}^{i}>x_{2}\left(r_{1}^{i}, r_{2}^{i}\right)$ we have from (9) that $r_{2}^{i}=r_{2}^{i+1}$. Hence,

$$
y_{2}\left(r_{1}^{i}, r_{2}^{i+1}\right) \geq r_{2}^{i}=r_{2}^{i+1}>y_{2}\left(r_{1}^{i+1}, r_{2}^{i+2}\right) .
$$

However, by Lemma B.6 we have $y_{2}\left(r_{1}^{i}, r_{2}^{i+1}\right)=y_{2}^{3, \text { I }}$, which by Lemma B.2 implies $y_{2}\left(r_{1}^{i}, r_{2}^{i+1}\right)=y_{2}\left(r_{1}^{i+1}, r_{2}^{i+2}\right)$. This contradicts the above.

- $\left(r_{1}^{i}, r_{2}^{i+1}\right) \in Q_{3, \mathrm{II}}$ : By Lemma B.7 we have $y_{1}\left(r_{1}^{i}, r_{2}^{i+1}\right)=y_{1}^{3, \mathrm{II}}$. By Lemma B.1 and the construction of $x^{3, I I}$, we then have

$$
\begin{aligned}
x_{2}\left(r_{1}^{i}, r_{2}^{i}\right) & =\frac{\delta\left(1+\lambda_{2} r_{2}^{i+1}\right)}{1+\lambda_{2}}-\frac{\delta y_{1}\left(r_{1}^{i}, r_{2}^{i+1}\right)}{1+\lambda_{2}} \\
& =\frac{\delta\left(1+\lambda_{2} r_{2}^{i+1}\right)}{1+\lambda_{2}}-\frac{\delta y_{1}^{3, \text { II }}}{1+\lambda_{2}} \\
& =\frac{\delta\left(y_{2}^{3, \mathrm{II}}+\lambda_{2} r_{2}^{i+1}\right)}{1+\lambda_{2}} \\
& =x_{2}^{3, \mathrm{II}},
\end{aligned}
$$

contradicting $x_{2}\left(r_{1}^{i}, r_{2}^{i}\right) \neq x_{2}^{3, \mathrm{II}}$. 
- $\left(r_{1}^{i}, r_{2}^{i+1}\right) \in Q_{3, \mathrm{III}}:$ By Lemma B.11 and the definition of $y_{1}^{3, \text { III }}$ this implies

$$
y_{1}\left(r_{1}^{i}, r_{2}^{i+1}\right)=y_{1}^{3, \mathrm{III}}=\frac{\delta}{\mu_{1}}-\frac{\delta}{\mu_{1}} x_{2}^{3, \mathrm{III}} .
$$

By Lemma B.1 we have

$$
y_{1}\left(r_{1}^{i}, r_{2}^{i+1}\right)=\frac{\delta}{\mu_{1}}-\frac{\delta}{\mu_{1}} x_{2}\left(r_{1}^{i+1}, r_{2}^{i+1}\right) .
$$

Hence, $x_{2}\left(r_{1}^{i+1}, r_{2}^{i+1}\right)=x_{2}^{3, \text { III }}$.

Since $r_{2}^{i}>x_{2}\left(r_{1}^{i}, r_{2}^{i}\right)$, we have from (9) that $r_{2}^{i+1}=r_{2}^{i}$. Then

$$
x_{2}\left(r_{1}^{i+1}, r_{2}^{i+1}\right) \geq r_{2}^{i+1}=r_{2}^{i}>x_{2}\left(r_{1}^{i}, r_{2}^{i}\right) .
$$

By Lemma B.2 this implies $x_{2}\left(r_{1}^{i}, r_{2}^{i}\right)>x_{2}^{3, \text { II }}$. Since $r_{2}^{i}>x_{2}\left(r_{1}^{i}, r_{2}^{i}\right)$ and $r_{2}^{i}=r_{2}^{i+1}$ this implies $r_{2}^{i+1}>x_{2}^{3, \text { II }}$. That is,

$$
r_{2}^{i+1}>\frac{\delta\left(\mu_{1}-\delta+\lambda_{2} r_{2}^{i+1} \mu_{1}\right)}{\mu_{1}\left(1+\lambda_{2}\right)-\delta^{2}} .
$$

This is equivalent to $r_{2}^{i+1}>\frac{\delta\left(\mu_{1}-\delta\right)}{\mu_{1} \mu_{2}-\delta^{2}}=x_{2}^{3, \text { III }}$. Hence, $r_{2}^{i+1}>x_{2}\left(r_{1}^{i+1}, r_{2}^{i+1}\right)$, which implies $\left(r_{1}^{i}, r_{2}^{i+1}\right) \notin Q_{3, \mathrm{III}}$. This is a contradiction.

It follows that $x_{2}\left(r_{1}^{i}, r_{2}^{i}\right)=x_{2}^{3, \text { II }}$.

Similar results hold for $Q_{2, \mathrm{III}}$ and $Q_{1, \mathrm{III}}$.

Lemma B.14 If $\left(r_{1}^{i}, r_{2}^{i+1}\right) \in Q_{1, I I I}$ then $y_{1}\left(r_{1}^{i}, r_{2}^{i+1}\right)=y_{1}^{1, I I I}$.

Lemma B.15 If $\left(r_{1}^{i}, r_{2}^{i+1}\right) \in Q_{2, I I I}$ then $y_{1}\left(r_{1}^{i}, r_{2}^{i+1}\right)=y_{1}^{2, I I I}$.

Proofs are analogous to Lemma B.12 resp. B.13. We now prove the main result of this section.

Proof of Theorem 4.1. Let $\left(r_{1}^{i}, r_{2}^{i}\right)=P_{1, \mathrm{I}}$. By definition we have $r_{2}^{i}>$ $y_{2}\left(r_{1}^{i}, r_{2}^{i+1}\right)$ and $r_{1}^{i}>x_{1}\left(r_{1}^{i}, r_{2}^{i}\right)$. By Lemma B.5 this implies $r_{2}^{i}>y_{2}^{1, \mathrm{I}}$ and $r_{1}^{i}>x_{1}^{1, \mathrm{I}}$. Hence, $\left(r_{1}^{i}, r_{2}^{i}\right) \in X_{1, \mathrm{I}}$, from which it follows that $P_{1, \mathrm{I}} \subseteq X_{1, \mathrm{I}}$.

Similarly, by Lemmas B.5, B.8, B.9, B.10, B.12, and B.13, $\left(r_{1}^{i}, r_{2}^{i}\right) \in P_{\omega}$ implies $\left(r_{1}^{i}, r_{2}^{i}\right) \in X_{\omega}$ for each $\omega \in \Omega$. Hence, $P_{\omega} \subseteq X_{\omega}$ for each $\omega \in \Omega$. Since the sets $P_{\omega}$ are mutually exclusive and exhaustive, this implies

$$
P_{\omega}=X_{\omega} \text { for each } \omega \in \Omega \text {. }
$$

Hence, at times $t \in T_{\text {odd }}$ player 1's unique SPE strategy is to propose $x^{\omega}$ if $\left(r_{1}, r_{2}\right) \in X_{\omega}$. That is, to play strategy $\hat{f}$. Analogously, we have

$$
Q_{\omega}=X_{\omega} \text { for each } \omega \in \Omega,
$$


such that player 2's unique SPE strategy at times $t \in T_{\text {even }}$ is to propose $y^{\omega}$ if $\left(r_{1}, r_{2}\right) \in X_{\omega}$, i.e. to follow strategy $\hat{g}$.

It follows from part B. of the proof of Theorem 3.1 that player 1's unique optimal strategy at times $t \in T_{\text {even }}$ is to accept proposals which are at or above 2's SPE proposal, and to reject those which are not. (Rejecting player 2's proposal violates immediate acceptance.) That is, player 1's unique SPE strategy at times $t \in T_{\text {even }}$ is $\hat{f}$. Similarly, player 2's unique optimal strategy at times $t \in T_{\text {odd }}$ is to accept and reject proposals according to the strategy $\hat{g}$.

Thus, the strategy profile $(\hat{f}, \hat{g})$ is the unique SPE satisfying (U1)-(U3).

\section{Concave utility functions}

Let player $i$ 's preference for pie, $i=1,2$, be represented by a strictly increasing, concave von Neumann-Morgenstern utility function $v_{i}:[0,1] \rightarrow \mathbb{R}$. Since such a utility function is unique up to an affine transformation, we may assume that $v_{i}(0)=0$ and $v_{i}(1)=1$. Furthermore, define

$$
\tilde{Z}:=\left\{\left(v_{1}\left(z_{1}\right), v_{2}\left(z_{2}\right)\right) \mid z \in Z\right\} .
$$

In this more general setting, each finite path in $\bar{H}$ is associated with a utility outcome. That is, for all $h \in \bar{H} \backslash H^{\infty}$, we say that player $i, i=1,2$, obtains $v_{i}\left(\xi_{i}(h)\right)$, rather than $\xi_{i}(h)$. Note that due to rescaling, both players still attach a zero utility payoff to a disagreement path, and a utility payoff of one to agreement on a partition that gives them the whole pie. The loss aversion transformation $w$ is then applied to the utility outcome $v_{i}\left(\xi_{i}(h)\right)$. The reference point $r_{i}$ used in this transformation, is defined as the utility associated with the highest share player $i$ has rejected in the past. Like before, we have
a. $r_{1}>x_{1}>y_{1}: \delta_{1} x_{1}=y_{1}$.
b. $x_{1} \geq r_{1}>y_{1}: \delta_{1} x_{1}=\left(1+\lambda_{1}\right) y_{1}-\delta_{1} \lambda_{1} r_{1}$.
c. $x_{1}>y_{1} \geq r_{1}: \delta_{1} x_{1}=\mu_{1} y_{1}$.

and

$$
\begin{aligned}
& \text { i. } r_{2}>y_{2}>x_{2}: \delta_{2} y_{2}=x_{2} . \\
& \text { ii. } y_{2} \geq r_{2}>x_{2}: \delta_{2} y_{2}=\left(1+\lambda_{2}\right) x_{2}-\delta_{2} \lambda_{2} r_{2} \text {. } \\
& \text { iii. } y_{2}>x_{2} \geq r_{2}: \delta_{2} y_{2}=\mu_{2} x_{2} .
\end{aligned}
$$

where $x, y \in \tilde{Z}$. These equations again define a ninefold partition of the set of all possible reference point pairs, similar to the one depicted in Figure 1. Define $\tilde{\Omega}:=\{$ a.i.,,$\ldots$, c.iii. $\}$, and denote the associated sets again by $X_{\omega}, \omega \in \tilde{\Omega}$. It can be shown that the system of equations yields a unique solution $\left(x^{\omega}, y^{\omega}\right)$ in 
$\tilde{Z} \times \tilde{Z}$ for each $\omega \in \tilde{\Omega}$. Let $h^{t}=\left(h^{t-1}, z\right)$ with $z \in \tilde{Z}$. Then for all $\omega \in \tilde{\Omega}$, define the strategy pair $(\breve{f}, \breve{g})$ for $t \in T_{\text {odd }}$ by

$$
\breve{f}^{t}\left(h^{t-1}\right)=x^{\omega}, \quad \breve{g}^{t}\left(h^{t}\right)=\left\{\begin{array}{ll}
\mathrm{Y} & \text { if } z_{2} \geq x_{2}^{\omega} \\
\mathrm{N} & \text { otherwise. }
\end{array}, \quad \text { if }\left(r_{1}\left(h^{t-1}\right), r_{2}\left(h^{t-1}\right)\right) \in X_{\omega},\right.
$$

and for $t \in T_{\text {even }}$ by

$$
\breve{f}^{t}\left(h^{t}\right)=\left\{\begin{array}{ll}
\mathrm{Y} & \text { if } z_{1} \geq y_{1}^{\omega} \\
\mathrm{N} & \text { otherwise }
\end{array}, \quad \breve{g}^{t}\left(h^{t-1}\right)=y^{\omega}, \quad \text { if }\left(r_{1}\left(h^{t-1}\right), r_{2}\left(h^{t-1}\right)\right) \in X_{\omega} .\right.
$$

We obtain the following result.

Theorem C.1 The strategy profile $(\breve{f}, \breve{g})$ is an SPE.

Proof. Observe that Lemma A.1 continues to hold if players' utility functions are concave. Hence, the game is still continuous at infinity. The proof of Theorem C.1 is then analogous to that of Theorem 3.1.

It follows that the partition obtained at the beginning of the game, where reference points are zero, is given by $x^{\text {c.iii. }}$. Henceforth, we drop the superscript c.iii., and write the solution as $x$. Note that we may again generalize the above results to the case where the time lapse between proposals is $\Delta$. Thus, we have

$$
\psi\left(x_{1}\right)=x_{2}=\frac{\delta_{2}^{\Delta}}{\mu_{2}} y_{2}^{\text {c.iii. }}=\frac{\delta_{2}^{\Delta}}{\mu_{2}} \psi\left(y_{1}^{\text {c.iii. }}\right)=\frac{\delta_{2}^{\Delta}}{\mu_{2}} \psi\left(\frac{\delta_{1}^{\Delta}}{\mu_{1}} x_{1}\right)
$$

where $\mu_{i}=1+\lambda_{i}\left(1-\delta_{i}^{\Delta}\right)$. Then by extending Proposition 4 from Binmore et al. (1986), we generalize the result that the equilibrium partition converges to an asymmetric Nash bargaining solution partition as $\Delta$ goes to zero, to the case where players have concave utility functions.

Let $z^{N}$ be the asymmetric Nash solution

$$
z^{N}=\arg \max _{z \in \tilde{Z}} z_{1}^{\alpha} z_{2}^{1-\alpha},
$$

where $\alpha=\frac{\left(1+\lambda_{2}\right) \log \delta_{2}}{\left(1+\lambda_{1}\right) \log \delta_{1}+\left(1+\lambda_{2}\right) \log \delta_{2}}$. Observe that $z^{N}$ is uniquely defined by

- $z_{2}^{N}=\psi\left(z_{1}^{N}\right)$, and

- $\left|\psi_{-}^{\prime}\left(z_{1}^{N}\right)\right| \leq \frac{\alpha}{1-\alpha} \frac{z_{2}^{N}}{z_{1}^{N}} \leq\left|\psi_{+}^{\prime}\left(z_{1}^{N}\right)\right|$,

where $\psi_{-}^{\prime}$ and $\psi_{+}^{\prime}$ are the left- resp. righthand side derivatives of $\psi$. Let $x \rightarrow \bar{x}$ as $\Delta \rightarrow 0$. Since $\psi$ is continuous on $[0,1]$, we have that $\bar{x}_{2}=\psi\left(\bar{x}_{1}\right)$. Furthermore, since $\psi$ is decreasing and concave, we have

$$
\left|\psi_{-}^{\prime}\left(\bar{x}_{1}\right)\right| \leq \lim _{\Delta \rightarrow 0}\left|\frac{\psi\left(x_{1}\right)-\psi\left(\frac{\delta_{1}^{\Delta}}{\mu_{1}} x_{1}\right)}{x_{1}-\frac{\delta_{1}^{\Delta}}{\mu_{1}} x_{1}}\right| \leq\left|\psi_{+}^{\prime}\left(\bar{x}_{1}\right)\right|,
$$


and, using l'Hôpital's rule,

$$
\begin{aligned}
\lim _{\Delta \rightarrow 0}\left|\frac{\psi\left(x_{1}\right)-\psi\left(\frac{\delta_{1}^{\Delta}}{\mu_{1}} x_{1}\right)}{x_{1}-\frac{\delta_{1}^{\Delta}}{\mu_{1}} x_{1}}\right| & =\lim _{\Delta \rightarrow 0}\left|\frac{\left(\frac{\delta_{2}^{\Delta}}{\mu_{2}}-1\right) \psi\left(\frac{\delta_{1}^{\Delta}}{\mu_{1}} x_{1}\right)}{\left(1-\frac{\delta_{1}^{\Delta}}{\mu_{1}}\right) x_{1}}\right| \\
& =\lim _{\Delta \rightarrow 0}\left|\frac{\frac{\left(1+\lambda_{2}\right) \delta_{2}^{\Delta} \log \delta_{2}}{\mu_{2}^{2}} \psi\left(\frac{\delta_{1}^{\Delta}}{\mu_{1}} x_{1}\right)+\left(\frac{\delta_{2}^{\Delta}}{\mu_{2}}-1\right) \frac{d \psi\left(\frac{\delta_{1}^{\Delta}}{\mu_{1}} x_{1}\right)}{d \Delta}}{-\frac{\left(1+\lambda_{1}\right) \delta_{1}^{\Delta} \log \delta_{1}}{\mu_{1}^{2}} x_{1}+\left(1-\frac{\delta_{1}^{\Delta}}{\mu_{1}}\right) \frac{d x_{1}}{d \Delta}}\right| \\
& =\frac{\left(1+\lambda_{2}\right) \log \delta_{2}}{\left(1+\lambda_{1}\right) \log \delta_{1}} \times \frac{\psi\left(\bar{x}_{1}\right)}{\bar{x}_{1}} \\
& =\frac{\alpha}{1-\alpha} \times \frac{\bar{x}_{2}}{\bar{x}_{1}} .
\end{aligned}
$$

It follows that $\bar{x}=z^{N}$.

\section{References}

[1] Ken Binmore, Ariel Rubinstein, Asher Wolinsky. The Nash bargaining solution in economic modelling. The RAND Journal of Economics, 17(2):176$188,1986$.

[2] Olivier Compte, Philippe Jehiel. Bargaining with reference dependent preferences. mimeo CERAS, 2003.

[3] John C. Harsanyi, Reinhard Selten. A generalized Nash solution for twoperson bargaining games with incomplete information. Management Science, 18(5):80-106, 1972.

[4] Ebbe Hendon, Hans Jørgen Jacobsen, Birgitte Sloth. The one-shotdeviation principle for sequential rationality. Games and Economic Behavior, 12(2):274-282, 1996.

[5] Ehud Kalai. Nonsymmetric Nash solutions and replications of 2-person bargaining. International Journal of Game Theory, 6(3):129-133, 1977.

[6] Daniel Kahneman, Amos Tversky. Prospect theory: an analysis of choice under risk. Econometrica 47(2):263-291, 1979.

[7] Daniel Kahneman, Amos Tversky. Choices, Values, and Frames. American Psychologist 39(4):341-350, 1984.

[8] Richard Kihlstrom, Alvin Roth, David Schmeidler. Risk aversion and solutions to Nash's bargaining problem, in Game theory and mathematical economics by O. Moeschlin and D. Pallaschke (eds.), Amsterdam: NorthHolland, 1981. 
[9] Veronika Köbberling, Hans Peters. The effect of decision weights in bargaining problems. Journal of Economic Theory 110(1):154-175, 2003.

[10] Duozhe Li. Bargaining with history-dependent preferences. Journal of Economic Theory, 136(1):695-708, 2007.

[11] John Nash, Jr. The bargaining problem. Econometrica, 18(2):155-162, 1950.

[12] Alvin Roth. A note on risk aversion in a perfect equilibrium model of bargaining. Econometrica 53(1):207-211, 1985.

[13] Ariel Rubinstein. Perfect equilibrium in a bargaining model. Econometrica, 50(1):97-109, 1982.

[14] Zvi Safra, Itzhak Zilcha. Bargaining solutions without the expected utility hypothesis. Games and Economic Behavior, 5(2):288-306, 1993.

[15] Jonathan Shalev. Loss aversion and bargaining. Theory and Decision, 52(3):201-232, 2002.

[16] Ingolf Ståhl. Bargaining Theory. Economics Research Institute, Stockholm School of Economics, 1972. 